\title{
Effect of Surface Roughness on Heat Transfer and Entropy Generation of Mixed Convection in Nanofluid
}

\author{
Kevin Ting \\ School of Engineering \\ Newcastle University \\ Newcastle, NE1 7RU, UK \\ E-mail: kevintingx@gmail.com
}

\author{
Aloke K. Mozumder \\ Department of Mechanical Engineering, \\ Bangladesh University of Engineering and Technology \\ Dhaka, Bangladesh \\ E-mail: aloke@me.buet.ac.bd
}

\section{Prodip K. Das ${ }^{1}$}

School of Engineering

Newcastle University

Newcastle, NE1 7RU, UK

E-mail: prodip.das@newcastle.ac.uk

\begin{abstract}
In this study, mixed convective heat transfer and entropy generation of $\mathrm{Al}_{2} \mathrm{O}_{3}$-water in a lid-driven square cavity with roughness elements on the bottom surface have been studied. The vertical sidewalls of the cavity are adiabatic and horizontal walls are maintained at a constant temperature, while the top wall is moving at a constant velocity. Various Reynolds numbers, Rayleigh numbers, and nanoparticles concentrations have been considered. The wavy bottom wall of the cavity is determined by the number and amplitude of the roughness elements. It has been observed that the larger amplitude reduces the heat transfer rate while increasing the total entropy generation and the average Bejan number (Beavg). Conversely, the roughness elements reduce the
\end{abstract}

\footnotetext{
${ }^{1}$ Corresponding Author: Tel. 0191208 6170; Email: prodip.das@ newcastle.ac.uk
} 
heat transfer rate and total entropy generation while increasing the Be avg. It has been further observed that the amplitude has a greater effect on the entropy generation and $B e_{\text {avg }}$ than the number of roughness elements. In addition, increasing the Reynolds and Rayleigh numbers increases the average Nusselt number and total entropy generation, while reducing Beavg. Addition of nanoparticles in a base fluid increases the heat transfer while minimizes the total entropy generation. The Beavg rises with nanoparticle concentrations. The lowest entropy generation for nanofluid could be achieved at low Rayleigh number and Reynolds number with a fixed number and amplitude of the roughness elements. In the cases studied, total entropy generation is greatly affected by heat transfer irreversibility while fluid friction irreversibility plays a minor role in the total entropy generation enhancement.

Keywords: Mixed convection, Nanofluid, Surface roughness, Entropy generation, Bejan number

\section{INTRODUCTION}

Conventional fluids used for heat transfer applications such as water, mineral oils, and ethylene glycol have low thermal conductivity. Thus, there is a great need to develop new kinds of fluids that are more effective in terms of heat transfer performances, which lead to researchers developing various nanofluids. Nanofluids are fluids containing metallic or non-metallic nanometer-sized particles suspended stably and uniformly in a base fluid. The use of nanoparticles in nanofluids results in higher thermal conductivities and heat transfer coefficients as compared to the base fluid. A study by Lee et al. [1] indicated the thermal conductivity of $\mathrm{Al}_{2} \mathrm{O}_{3}$-water and $\mathrm{Cu}$-water nanofluids increases with nanoparticles concentration. The presence of nanoparticles alters the transport characteristics and heat transfer performance. The heat transfer characteristics of the nanofluid also depend on the shape, size, thermo-physical properties of nanoparticles, and the thermophysical properties of the base fluid. Even though many experimental studies have been carried out for 
nanofluids showing their better thermal performances [1-7], further studies are required to prove that the enhancement of thermal conductivity is beneficial for mixed convection in the enclosure.

Natural convection and forced convection are the two ends for the convective heat transfer. In natural convection, fluid motion is driven by the difference in temperature of a surface and fluid. In forced convection, an external force such as a moving plate drives the fluid motion. Mixed convection is due to the presence of both conditions. Thus, mixed convection can be preferred as a mode to enhance heat transfer. A study of natural convection of Cu-water nanofluid in the two-dimensional enclosure was examined by Khanafer et al. [8]. It was discovered that in any given Grashof number, heat transfer in the enclosure increases with nanoparticles concentration. Oztop et al. [9] studied the effect of nanofluids on natural convection. It was shown that the increase in nanoparticle concentration increases the heat transfer rate. Many numerical studies on the enhancement of buoyancy-driven natural convection of nanofluids and other fluids in various geometries and boundary conditions had been conducted [10-21].

Lid-driven mixed convection flow is used widely to simulate processes, such as cooling microelectronic devices, solar collectors, food processing, lubrication purposes, drying applications, and nuclear reactors. Mixed convection of nanofluids in an enclosure is a challenging problem due to the complex interactions between inertia, viscous, and buoyancy forces of the nanoparticles. Fluid flow and heat transfer by using mixed convection driven by buoyancy and shear in a cavity filled with a base fluid or nanofluid have been studied recently. According to the study carried out by Basak et al. [22], the effect of natural convection decreases while forced convection increases with the higher Reynolds number. Studies done by Buongiorno [23], Tiwari and Das [24], Nemati et al. [25], 
Talebi et al. [26], Mansour et al. [27], Nayak et al. [12, 28], Hussain et al. [29], and Cong et al. [30] are showing that the heat transfer rate increases with increasing nanoparticles concentration. Sortiji et al. [31] examined the mixed convection heat transfer of $\mathrm{Al}_{2} \mathrm{O}_{3}$-water nanofluid in a ventilated cavity. It was shown that the average Nusselt number increases with the Reynolds number, Richardson number, and nanoparticle's concentration. Al-Amiri et al. [32] studied the effect of the wavy bottom wall on the mixed convective heat transfer in a square cavity. It was suggested that large wavy surface amplitude enhanced heat transfer mechanism in a lid-driven cavity at low Richardson number.

Entropy is the degree of disorder in an enclosed system where the transfer of energy takes place in a single direction, also known as an irreversible process. The entropy generation signifies the irreversibility of the process, which determines the performance of thermal machines. On the other hand, the thermodynamic efficiency of a system is reduced due to the entropy generation. In every convective heat transfer problem, there will always be a tradeoff between heat transfer irreversibility and frictional force irreversibility [33, 34].

The problem of entropy generation in cavities filled with nanofluids has attracted significant attention. A number of studies have been conducted focusing on the entropy generation of natural convection heat transfer [35-37]. The work of Cho et al. [38] showed that increasing nanoparticle concentration reduces the total entropy generation. His study also pointed out that larger amplitude and wavelength of the wavy surface increase the total entropy generation and Bejan number. The studies of Oliveski et al. [39] showed that the total entropy generation subjected to natural convection in the steady-state increases linearly with aspect ratio, and irreversibility ratio, exponentially with the Rayleigh number. In addition, the entropy generation due to viscous effects increases exponentially with the Rayleigh number. Khorasanizadeh et al. [40] studied mixed convection and entropy 
generation in a lid-driven square cavity. It was highlighted that the increase of Reynolds number increases the heat transfer term and viscous term of entropy generation. A similar result is obtained by Nayak et al. [28]. Their study also mentioned that the increase in buoyancy effect increases the entropy due to heat transfer. Mamourian et al. [41] studied mixed convection and entropy generation in a wavy bottom lid-driven square cavity using Taguchi method. The result of his work indicates the optimum parameters to maximize the heat transfer in terms of nanoparticle concentration, the wavelength of the wavy surface, and the Richardson number.

There are several numerical investigations on the entropy generation of nanofluids in cavities utilizing mixed convection process, but uncertainties (particularly benefits of using nanofluids, the addition of surface features, and the impact nanoparticles on the entropy generation) still exist in a square cavity with the wavy bottom surface. Thus, the aim of the present work is to study the heat transfer and entropy generation in mixed convection processes in the cavity with sinusoidal roughness elements on the bottom wall through numerical simulation. A square cavity filled with $\mathrm{Al}_{2} \mathrm{O}_{3}$-water nanofluid with a lid moving from left to right at constant velocity has been considered. The amplitude and number of the roughness elements are used to define the sinusoidal geometry. For various simulations, several values of Rayleigh number, Reynolds number, and nanoparticle concentration are considered. The entropy generations, including irreversibility due to heat transfer and fluid friction, are also investigated along with the Bejan number. 


\section{GOVERNING EQUATIONS AND PROBLEM FORMULATION}

Figure 1 shows a schematic diagram of a lid-driven square cavity with roughness elements intruded at the bottom wall, where $H$ and $L$ denote the height and length of the cavity, respectively. The scaled amplitude and number of roughness elements with respect to the cavity length and height are denoted by $A$ and $N$, respectively. The top wall of the cavity is moving from left to right with a uniform velocity of $u_{0}$. The temperature of the top wall is kept constant at $T_{\min }$, while the roughness elements have a temperature of $T_{\max }$. The two vertical walls are considered to be the adiabatic and non-slip condition is applied. The nanofluids are considered a Newtonian, incompressible fluid, and the flow is laminar. The nanoparticles are assumed to have uniform size and shape. The radiative heat transfer and chemical reaction between the base fluid and nanoparticles and the viscous dissipation in the heat transport equation have been neglected. The area of the cavity is kept constant, while the $A$ varies from 0 to 0.15 and $N$ varies from 0 to 10 . The dimensionless velocity components $(U$ and $V)$ and temperature $(\theta)$ in Figure 1 are expressed as:

$U=\frac{u}{u_{0}}, V=\frac{v}{u_{0}}, \theta=\frac{T-T_{\min }}{T_{\max }-T_{\min }}$

The conservation equations of mass, momentum, and energy for two-dimensional, laminar, steady-state mixed convection fluid flow and heat transfer are used as the governing equations in this study, using the Navier-Stokes equations with the Boussinesq approximation in the $y$-direction. These equations are expressed as [30, 42]:

Continuity:

$\frac{\partial u}{\partial x}+\frac{\partial v}{\partial y}=0$ 
Momentum (horizontal):

$u \frac{\partial u}{\partial x}+v \frac{\partial u}{\partial y}=-\frac{1}{\rho_{n f}} \frac{\partial p}{\partial x}+\frac{\mu_{n f}}{\rho_{n f}}\left(\frac{\partial^{2} u}{\partial x^{2}}+\frac{\partial^{2} u}{\partial y^{2}}\right)$

Momentum (vertical):

$u \frac{\partial v}{\partial x}+v \frac{\partial v}{\partial y}=-\frac{1}{\rho_{n f}} \frac{\partial p}{\partial y}+\frac{\mu_{n f}}{\rho_{n f}}\left(\frac{\partial^{2} v}{\partial x^{2}}+\frac{\partial^{2} v}{\partial y^{2}}\right)+\beta_{n f} g\left(T-T_{\infty}\right)$

Energy:

$u \frac{\partial T}{\partial x}+v \frac{\partial T}{\partial y}=\frac{k_{n f}}{\rho_{n f} C_{p, n f}}\left(\frac{\partial^{2} T}{\partial x^{2}}+\frac{\partial^{2} T}{\partial y^{2}}\right)$

In the above equations, $u$ and $v$ are the horizontal and vertical velocities respectively, $p$ is the pressure, $\mu_{n f}$ is the effective dynamic viscosity of nanofluid, $\rho_{n f}$ is density of nanofluid, $\beta_{n f}$ is thermal expansion coefficient of nanofluid, $T$ is the temperature, $g$ is gravitational acceleration, $k_{n f}$ is the effective thermal conductivity of nanofluid, and $C_{p, n f}$ is the effective heat capacity of nanofluid. The effective density, heat capacity, and thermal expansion coefficient of nanofluids are estimated using the effective medium theory, as it provides a reasonable estimate of effective properties and this theory has been widely used for multiphase systems [24-26, 43-50]. The effective density, heat capacity, and thermal expansion coefficient are expressed as:

Effective density:

$\rho_{n f}=(1-\varphi) \rho_{f}+\varphi \rho_{s}$

Effective heat capacitance: 
$C_{p, n f}=\frac{(1-\varphi)\left(\rho C_{p}\right)_{f}+\varphi\left(\rho C_{p}\right)_{s}}{\rho_{n f}}$

Effective thermal expansion:

$\beta_{n f}=\frac{(1-\varphi)(\rho \beta)_{f}+\varphi(\rho \beta)_{s}}{\rho_{n f}}$

The effective dynamic viscosity of the nanofluids is given by the Brinkman model [51]:

$\mu_{n f}=\mu_{f}(1-\varphi)^{-2.5}$

The effective heat conductivity is defined by the Maxwell model [52]:

$k_{n f}=\frac{k_{f}\left[k_{s}+2 k_{f}-2 \varphi\left(k_{f}-k_{s}\right)\right]}{k_{s}+2 k_{f}+\varphi\left(k_{f}-k_{s}\right)}$

where subscripts $f, s$, and $n f$ denote base fluid, nanoparticles, and nanofluid, respectively, and $\varphi$ is the volume fraction of nanoparticles in the base fluid. In this study, the nanoparticles $\left(\mathrm{Al}_{2} \mathrm{O}_{3}\right)$ are assumed to be in thermal equilibrium with the base fluid (water), and the thermo-physical properties of nanofluids are constant. Thermo-physical properties of water and $\mathrm{Al}_{2} \mathrm{O}_{3}$ nanoparticles are listed in Table $1[30,42]$.

A set of dimensionless numbers is used to alter the relation between the inertial and buoyancy forces. The Reynolds (Re), Rayleigh (Ra), Grashof ( $\mathrm{Gr}$ ), and Richardson (Ri) numbers are defined as:

$\mathrm{Re}=\frac{u_{0} H}{v_{n f}}, \mathrm{Ra}=\frac{g \beta_{n f} \Delta T L^{3}}{v_{n f} \alpha_{n f}}, \mathrm{Gr}=\frac{\beta g \Delta T L^{3}}{v_{n f}}, \mathrm{Ri}=\frac{\mathrm{Gr}}{\operatorname{Re}^{2}}$

where $\alpha_{n f}$ is the thermal diffusivity $\left(=k_{n f} /\left(\rho_{n f} C_{p, n f}\right)\right)$ and $v_{n f}$ is the kinematic viscosity of nanofluid. For different inertial forces considered in this study, the Reynolds numbers are varied between 100 and 1500 that changes the velocity of the moving lid. For different 
buoyancy forces considered, the Rayleigh numbers are varied between $10^{4}$ and $10^{7}$. The Grashof number shows the ratio of the buoyancy to the viscous force acting on the fluid, while the Richardson number shows the significance of natural convection related to forced convection. Natural convection dominates the heat transfer regime when $\mathrm{Ri}>10$ whereas the effect of forced convection is dominant when $\mathrm{Ri}<0.1$. Both types of convection are said to have an equivalent effect when $0.1<\mathrm{Ri}<10$.

To determine the heat transfer performance, local and average Nusselt numbers are computed. The Nusselt number $(\mathrm{Nu})$ is defined as the ratio of convective to conductive heat transfer across (normal to) the boundary. The local Nusselt number $\left(\mathrm{Nu}_{H}\right)$ along the rough bottom wall is calculated as:

$\mathrm{Nu}_{H}=\frac{h_{n f} L}{k_{f}}$

where $h_{n f}$ is the effective heat transfer coefficient. The average Nusselt number $\left(\mathrm{Nu}_{\text {avg }}\right)$ is calculated through the integration of $\mathrm{Nu}_{H}$ over the roughness elements, as follows:

$$
\mathrm{Nu}_{\mathrm{avg}}=\frac{1}{A} \int \mathrm{Nu}_{H} \mathrm{~d} A
$$

In the convection process, the entropy generation is associated with heat transfer and fluid friction. The local entropy generation $\left(s_{g e n}\right)$ is calculated using the expression suggested by Bejan [33]:

$$
s_{g e n}=\frac{k_{n f}}{T_{o}^{2}}\left[\left(\frac{\partial T}{\partial x}\right)^{2}+\left(\frac{\partial T}{\partial y}\right)^{2}\right]+\frac{\mu_{n f}}{T_{0}}\left[2\left\{\left(\frac{\partial u}{\partial x}\right)^{2}+\left(\frac{\partial v}{\partial y}\right)^{2}\right\}+\left(\frac{\partial u}{\partial y}+\frac{\partial v}{\partial x}\right)^{2}\right]
$$

where $T_{o}=0.5\left(T_{\max }+T_{\min }\right)$ is the reference temperature. 
The first term in the above equation represents the dimensional entropy generation due to heat transfer, while the second term is the dimensional entropy generation due to fluid friction. By using the dimensionless parameters introduced in Eq. (1), the local entropy generation equation is transformed into the non-dimensional form as:

$$
\begin{aligned}
& S_{g e n}^{\prime}=\left[\left(\frac{\partial \theta}{\partial X}\right)^{2}+\left(\frac{\partial \theta}{\partial Y}\right)^{2}\right]+\chi\left[2\left\{\left(\frac{\partial U}{\partial X}\right)^{2}+\left(\frac{\partial V}{\partial Y}\right)^{2}\right\}+\left(\frac{\partial U}{\partial Y}+\frac{\partial V}{\partial X}\right)^{2}\right] \\
& S_{g e n}^{\prime}=S_{g e n, h}^{\prime}+S_{g e n, f}^{\prime} \\
& \phi=\frac{\mu_{f} T_{0} u_{0}^{2}}{k_{f} \Delta T^{2}} \\
& \chi=\phi \times \frac{k_{f}}{k_{n f}} \times \frac{\mu_{n f}}{\mu_{f}}=\frac{\mu_{n f} T_{0} u_{0}^{2}}{k_{n f} \Delta T^{2}}
\end{aligned}
$$

where $S^{\prime}$ gen is the non-dimensional entropy generation and $\phi$ is the base fluid irreversibility distribution ratio. In this study, $\phi$ is taken as $10^{-4}$. A similar value of $\phi$ was considered by Nayak et al. $[12,28]$. Note that $\phi$ is an adjustable parameter and for a given fluid that varies according to the temperature difference number, $\Delta T / T_{o}$. Nanofluid's irreversibility distribution ratio, $\chi$ varies corresponding to the volume fraction of nanoparticles.

The dimensionless volume-averaged entropy generation $\left(S_{g e n}\right)$ is obtained through the integration of the scaled local entropy generation over the whole domain.

$$
S_{g e n}=\frac{1}{V} \int S_{g e n}^{\prime} \mathrm{d} V
$$

The Bejan number (Be), which is also known as irreversibility distribution, is the ratio of entropy generation due to the heat transfer to total entropy generation, defined as [37]:

$$
\mathrm{Be}=\frac{S_{g e n, h}^{\prime}}{S_{g e n}^{\prime}}
$$


The average Bejan number ( $\mathrm{Be}_{\mathrm{avg}}$ ) is obtained by integrating the local Bejan number over the whole domain.

$\mathrm{Be}_{\text {avg }}=\frac{1}{V} \int \operatorname{Bed} V$

When $\mathrm{Be}_{\text {avg }}$ approaches to 1 , the irreversibility due to heat transfer dominates the entropy generation. The fluid friction irreversibility is said to be dominant when $\mathrm{Be}_{\mathrm{avg}}$ is smaller than $1 / 2$. When $\mathrm{Be}_{\text {avg }}$ is $1 / 2$, the distributions of entropy generation due to heat transfer and fluid flow friction are equal [37].

\section{NUMERICAL MODELLING}

The numerical solution is obtained by solving the governing equations using commercial finite volume-based software, ANSYS-FLUENT. A second-order upwind scheme is used for the spatial discretization of the aforementioned equations. The velocity-pressure coupling is done by the SIMPLE algorithm and a pressure-based solver is used to computing the solution. The solution of the governing equations is considered converged when the residuals are lower than $10^{-6}$ for the mass and momentum equations and smaller than $10^{-8}$ for the energy equation.

\section{Model Validation}

In order to identify the accuracy of the heat transfer results, the numerical method is evaluated by comparing with the results of other literature. First, a simulation is carried out for natural convection in a square cavity filled with an air of Prandtl number $(\operatorname{Pr})=0.7$ similar to Dixit and Babu [53] and De Vahl Davis [54]. The cavity considered to have 
adiabatic horizontal walls and heated vertical walls with the left wall kept at a higher temperature. The results obtained for the average Nusselt number on the left wall achieved a good agreement with both authors as shown in Figure 2.

In addition, a case of natural convection utilizing 5\% Cu-water nanofluids with water of Prandtl number $(\mathrm{Pr})=6.2$ as a base fluid is performed at Grashof number, $\mathrm{Gr}=10^{5}$. This case is compared with the data of Khanafer et al. [8]. The square cavity considered has adiabatic horizontal walls and heated vertical walls with the left wall kept at a higher temperature. The temperature profile and velocity profiles along the mid-section of the cavity were plotted. It can be seen in Figure 3 that the peak values of velocity components of the present study are less than the results of Khanafer et al. [8]. This is due to the different software used to perform the simulations. Overall, the solutions of the present numerical code were in excellent agreement with results from the literature.

The accuracy of present numerical code is further validated by comparing the results with Nayak et al. [28] for mixed convection of Cu-water nanofluid utilizing various volume fractions of nanoparticles at $\operatorname{Re}=100$ and $\mathrm{Gr}=10^{3}$. The top lid-driven square cavity has adiabatic vertical walls and heated horizontal walls with the bottom wall kept at a higher temperature. The results obtained from the present numerical code compared well with results from the data of Nayak et al. [28] as shown in Figure 4. Once again, the present numerical results show a good agreement with the literature data for a wide range of nanoparticle concentrations.

The numerical model for entropy generation is also validated by making a case study for natural convection of air for $\operatorname{Pr}=0.7$ at $\mathrm{Ra}=10^{3}$ to compare with the data of llis et al. [55]. The considered domain, in this case, is a square cavity with adiabatic horizontal walls and heated vertical walls, which is identical to the geometry used by llis et al. [55]. A 
qualitative comparison of the present data with the literature data is shown in Figure 5. It is evident from Figure 5 that the local entropy generation plot due to heat transfer and fluid friction for this problem is similar to the result presented by llis et al. [55].

\section{Mesh Independence Test}

A mesh independence test is made to obtain an optimum mesh size in order to obtain the results' consistency. This is done by comparing the average Nusselt number along the wavy bottom wall for various mesh sizes utilizing triangular mesh. The results of the mesh independency test are illustrated in Figure 6 for two Rayleigh numbers $\left(10^{5}\right.$ and $\left.10^{7}\right)$ at $\operatorname{Re}=10^{3}$ and $\phi=1 \%$ of $\mathrm{Al}_{2} \mathrm{O}_{3}$-water nanofluid in a square cavity with roughness elements of 8 and scaled amplitude of 0.05 . As shown in Figure 6 for $\mathrm{Ra}=10^{5}$, further increment in mesh volumes above 46220 has no observable changes on average Nusselt number as it had come to a nearly constant value. Thus, a mesh volume in the order of 50000 seems sufficient to achieve a mesh independent result for $\mathrm{Ra}=10^{5}$. However, the same mesh volume is not sufficient for the cases of higher Rayleigh numbers, particularly Ra $>5 \times 10^{6}$. As shown in Figure 6 for $\mathrm{Ra}=10^{7}$, a mesh volume in the order of 100000 is needed to achieve a result with less than $1 \%$ error. Even with a higher mesh volume for $\mathrm{Ra}=10^{7}$, the percent of error is higher compared with the result of $\mathrm{Ra}=10^{5}$ at a mesh volume of 46220 . Thus, most of the simulations in the present study are carried out using mesh size with a volume in the order of 50000 for $\mathrm{Ra}<5 \times 10^{6}$, while a higher mesh volume was used for the cases of $\mathrm{Ra}>5 \times 10^{6}$. 


\section{RESULTS AND DISCUSSIONS}

In this section, numerical results of mixed convective heat transfer and entropy generation of $\mathrm{Al}_{2} \mathrm{O}_{3}$-water nanofluids in a lid-driven cavity with roughness elements at the bottom wall are presented. A set of graphs, thermal contours, and streamlines are shown to illustrate the relationships between different parameters: Rayleigh number, Reynolds number, amplitude and number of roughness elements, and nanoparticles concentration.

\section{Effects of Scaled Amplitude and Number of Roughness Elements}

Figure 7 shows the variation of the average Nusselt number along the bottom surface as a function of roughness element number for three values of scaled amplitude when Reynolds number, $\operatorname{Re}=1000$, Rayleigh number, $\operatorname{Ra}=10^{5}$ and volume fraction, $\varphi=1 \%$ $\mathrm{Al}_{2} \mathrm{O}_{3}$-water nanofluids are used. Based on the obtained data, the average Nusselt number is the largest at $A=0.05$ among the tested amplitudes. $\mathrm{Nu}_{\text {avg }}$ decreases with the increase in $A$. Furthermore, the addition of roughness elements reduces heat transfer performance. This is further analyzed by comparing the isothermal plots (shown in Figures 8 and 9) for various scaled amplitudes and the number of roughness elements.

Isothermal plots of $1 \% \mathrm{Al}_{2} \mathrm{O}_{3}$-water nanofluid for different amplitudes at $\mathrm{N}=8, \mathrm{Re}=$ 1000 , and $\mathrm{Ra}=10^{5}$ and isothermal plots of $1 \% \mathrm{Al}_{2} \mathrm{O}_{3}$-water nanofluid for different number of roughness elements at $A=0.10, \operatorname{Re}=1000$, and $\mathrm{Ra}=10^{5}$ are presented in Figure 8 and Figure 9, respectively. Figure 8 illustrates that with higher amplitude of roughness elements, the flow cannot reach the bottom part of the cavity. This leads to a decreased convective heat transfer between the nanofluid and roughness elements. Equivalently, it lowered the relative strength of convective to conductive heat transfer so results in lower $\mathrm{Nu}_{\text {avg. }}$. As seen 
in Figure 9, an increasing number of roughness elements interferes with the flow towards the bottom wall. The interference reduces the effectiveness of heat transfer along the surface, which eventually produces a lower $\mathrm{Nu}_{\text {avg, }}$ as flow reaches only the top of the roughness elements and the fluid at the bottom of the roughness elements remains stagnant. The effect is more pronounced near the center region of the bottom wall. This indicates that the addition of roughness elements number and increase in amplitude reduces the heat transfer from the wavy bottom wall to nanofluids.

The variation of average Nusselt number for various numbers and amplitudes of roughness elements could also be explained by observing the local heat flux distribution along with the roughness elements as presented in Figure 10. The number of peaks is corresponding to the number of roughness elements. It is discovered that $N=10$ demonstrates the greatest local Nusselt number $\left(\mathrm{Nu}_{H}\right)$. However, the average Nusselt number for $N=10$ is lower than $N=8$. This is because $N u_{\text {avg }}$ is obtained by the integration of local Nu then divided by relevant surface area. A wall with a higher number of roughness elements has a larger surface area. The increment of surface area for higher $N$ is greater than the enhancement of $\mathrm{Nu}$, hence, resulting in a lower $\mathrm{Nu}_{\text {avg }}$ value. The same is applied to the cavity with different roughness elements amplitude. The increase in roughness element amplitude increases the peak value of $\mathrm{Nu}_{H}$. This is because the thermal boundary layer is thinner near the peaks of roughness elements as highlighted in Figure 8 . It is also noticed that maximum local Nu moved towards the right side of the cavity. This phenomenon is due to the direction of the moving lid. It is evident that the insignificant effect of fluid flow near the lower corner of the cavity, which resulted in a lower heat transfer rate.

Figure 11 shows the effects of the number of roughness elements and scaled amplitude on average entropy generation $\left(S_{g e n}\right)$ and average Bejan number (Be $\left.{ }_{\text {avg }}\right)$. It is 
observed that there is an increasing trend in the total entropy generation with an increase in amplitude. When the amplitude of $N=8$ changes from 0.10 to 0.15 , it resulted in an enhancement of $5.5 \%$ in total entropy generation. On the other hand, the increase in roughness-elements number reduces the total entropy generation. Roughness elements of 10 produce a decrement of $0.5 \%$ in total entropy generation compared to roughness elements of 8 at $A=0.10$. An increase in number and amplitude of roughness elements augments the average Bejan number within the cavity. At $N=8$, an increment of $3.8 \%$ in $\mathrm{Be}_{\mathrm{avg}}$ is observed when the amplitude increases from 0.10 to 0.15 . Meanwhile, the increment in $\mathrm{Be}_{\mathrm{avg}}$ is only $2.7 \%$ with the addition of roughness elements number from 8 to 10 at $A=0.10$. It is worth noting that varying amplitude has a slightly higher effect than the number of roughness elements in the enhancement of heat transfer rate, entropy generation, and Bejan number. However, further studies are needed for precisely quantifying the effects of amplitude and roughness elements in a confined domain.

Figure 12 illustrates the Bejan plot for cavity with $A=0.10, N=8$ at $\operatorname{Re}=1000$ and $\mathrm{Ra}$ $=10^{5}$. Bejan number $(\mathrm{Be})$ is the ratio of heat transfer irreversibility to total entropy generation. The Bejan number of 1 indicates heat transfer dominant entropy while the Bejan number of 0 means fluid friction dominant entropy. The red contour (near the domain walls) represents $\mathrm{Be}=1$, while the blue contour (at the center of the domain) represents $\mathrm{Be}$ $=0$. The average Bejan number is determined by the distribution of Bejan number over the cavity. With a major part of the cavity occupied by heat transfer irreversibility, the average Bejan number is higher than 0.5 .

\section{Effect of Reynolds number}


Figure 13 depicts the effects of Reynolds number on the average Nusselt number for various numbers and scaled amplitude of roughness elements for $1 \% \mathrm{Al}_{2} \mathrm{O}_{3}$-water nanofluid at $\mathrm{Ra}=10^{5}$. It is observed that the increase in the Reynolds number increases $\mathrm{Nu}_{\text {avg }}$ for all cases with different amplitude and number of roughness elements. Since a higher Reynolds number indicates a higher lid velocity, it provides a larger inertial force to the nanofluids. Thus, the heat transfer is higher with the Reynolds numbers. However, the rough cavity shows a lower heat transfer than that of the smooth cavity. This could be explained by analyzing the isotherms and streamlines for various Reynolds numbers. Figure 14 shows the isotherms and streamlines for $\operatorname{Re}=100,500$ and 1000 at $N=8$ and $A=0.10$. As observed in Figure 14, the fluid only reaches the top of the roughness elements; thus, taking heat away only from the part of the roughness elements. As the fluid between the roughness elements is stagnant, the convective heat transfer from the rough cavity is lower than that of the smooth cavity.

The effects of Re, $N$, and $A$ on the average entropy generation $\left(S_{g e n}\right)$ and the average Bejan number $\left(\mathrm{Be}_{\text {avg }}\right.$ ) at $\mathrm{Ra}=10^{5}$ are shown in Figure 15 and Figure 16. It is revealed that entropy due to heat transfer and fluid friction, as well as total entropy generation, increases with Re. Increasing Re value enhances the forced convection that results in a greater difference between the wall and bulk temperature, hence, a higher local temperature gradient. This leads to a higher heat transfer entropy generation rate. Simultaneously, faster fluid flow leads to higher velocity gradient and larger shear stress that augments the fluid friction irreversibility. As seen from Figure 15, the rise in total entropy generation is mostly due to heat transfer irreversibility. Fluid friction irreversibility plays a little role in the entropy generation enhancement. The average Bejan number is not close to 1 despite the value of fluid friction entropy generation is relatively small compared to heat transfer 
entropy generation. It is because $\mathrm{Be}_{\mathrm{avg}}$ is determined by the overall distribution of Bejan number in the cavity as seen in Figure 12. It is noticed that increasing Re reduces $B e_{\text {avg. }}$ The entropy generation at $\mathrm{Re}=100$ is dominated by heat transfer irreversibility as $\mathrm{Be}_{\mathrm{avg}}$ is approaching unity. At $\operatorname{Re}=100$, the fluid has a low inertial force and thus weaker fluid friction irreversibility effect compared to that of higher Re. It should be noted that changing $A$ and $N$ has a negligible effect on $B_{\text {avg }}$ at $R e=100$.

As observed in Figure 15, the total entropy generation for the smooth bottom wall is almost similar to $A=0.05$ when $\operatorname{Re} \leq 500$. At $\operatorname{Re} \geq 1000$, there is a reduction of $S_{\text {gen }}$ when roughness elements are introduced. The entropy generation then increases with amplitude. The reduction of $S_{g e n}$ is more evident at higher Re as seen in Figure 15. Moreover, the entropy generation due to fluid friction drops when $A$ increases to 0.10 then rise again at $A$ $=0.15$. The Bejan number increases with the amplitude of roughness elements. The effect of $A$ on $\mathrm{Be}_{\text {avg }}$ is more distinct at higher Re. For instance, the increment of $B e_{\text {avg }}$ between a smooth wall and $A=0.15$ is $6 \%$ at $\operatorname{Re}=500$, while it is $15 \%$ at $\operatorname{Re}=1500$.

As shown in Figure 16, the increasing roughness element number increases the total entropy generation when Re $\leq 500$. However, a decreasing trend in the total entropy generation with the addition of roughness elements is observed for $\operatorname{Re} \geq 1000$. This is caused by the drop in $S_{g e n}$, as pointed out in Figure 15. If the roughness elements have a higher amplitude, an increasing trend would be observed. Additionally, entropy generation due to fluid friction decreases with $N$. At $500 \leq \operatorname{Re} \leq 1500$, the addition of roughness elements gives rise to $\mathrm{Be}_{\mathrm{avg}}$ and the increasing trend is more pronounced at higher $\mathrm{Re}$ number. The average Bejan number is enhanced by $4 \%$ with the inclusion of 10 roughness elements at $\operatorname{Re}=500$ while the increment is $11 \%$ at $\operatorname{Re}=1500$. It is notable that the augmentation of the average Bejan number by varying amplitude and number of roughness 
elements is more distinct at higher values of Re. As mentioned in the previous section, changing amplitude has a higher effect than the roughness elements number in the enhancement of heat transfer, entropy generation, and average Bejan number.

\section{Effect of Rayleigh Number}

Figure 17 shows the effect of the Rayleigh number on $\mathrm{Nu}_{\text {avg }}$ for various values $\mathrm{N}$ and A. The results are shown for $1 \% \mathrm{Al}_{2} \mathrm{O}_{3}$-water nanofluid at $\mathrm{Re}=1000$ for the Rayleigh number ranging from $10^{4}$ to $10^{7}$. The number of roughness elements is fixed at 8 for various values of $A$, whereas amplitude is set at 0.10 for various values of $N$. It is observed that $N u_{\text {avg }}$ slightly increases with the values of Ra but the effect is minute when $\mathrm{Ra} \leq 10^{5}$. This trend indicates the increased buoyancy effect enhances the heat transfer rate. Figure 17 further illustrates that $\mathrm{Nu}_{\text {avg }}$ attains a maximum value before it decays then rises up again at high Rayleigh number. It is noticed that larger $A$ shifts both the decay and rise in $\mathrm{Nu}_{\text {avg }}$ to a higher Ra value. The variations of average Nusselt number for the different number of roughness elements are having the same trend as seen in Figure 17 for various values of $N$. The transition from forced convection to mixed convection is visible in $\mathrm{Nu}_{\text {avg }}$ curves and is noticed when $\mathrm{Ra}$ is between $10^{6}$ and $10^{7}$. The qualitative trend of this transitional behavior is similar to the trends reported by other researchers [56-59]. The onset of mixed convection for a smooth cavity is noticed at $\mathrm{Ra}=9 \times 10^{5}$, while the addition of roughness elements shifts the onset of mixed convection towards a higher Rayleigh number. This effect is more prominent with the amplitudes of the roughness elements. As amplitude increases, the onset Rayleigh number also increases, while the onset Rayleigh number remains constant with the number of the roughness elements. 
The effects of Ra, scaled number and amplitude of roughness elements on entropy generation and average Bejan number at $\mathrm{Re}=1000$ are shown in Figure 18 and Figure 19. For $\mathrm{Ra} \leq 10^{6}$, the entropy generation increases with the Rayleigh number due to an increased buoyancy effect for $\mathrm{N}>0$. As mentioned before in Figure 11, entropy generation due to heat transfer $\left(S_{g e n, h}\right)$ increases with roughness elements amplitude. However, $S_{g e n, h}$ for a cavity with the smooth wall is slightly higher than that with the wavy bottom wall for Ra $\leq 10^{5}$. This behavior is pointed out in Figure 15 where the smooth wall has higher $S_{g e n, h}$ than roughness elements with $A=0.10$ at $\mathrm{Ra}=10^{5}$ and $\mathrm{Re}=1000$. Increasing $\mathrm{Ra}$ reduces $\mathrm{Be}_{\text {avg }}$ but the changes are hardly noticeable.

For $\mathrm{Ra}>10^{6}$, a decline in the total entropy generation is observed. They rise up again when $\mathrm{Ra}$ is approaching $10^{7}$. The minimum value of the entropy generation is lower when roughness elements have an amplitude of 0.10 . A surge in $B e_{a v g}$ is also noticed when $\mathrm{Ra}>$ $10^{6}$. It is found that the drop in entropy generation and a surge in $\mathrm{Be}_{\text {avg }}$ occur at a higher $\mathrm{Ra}$ value for larger $A$ while different roughness elements number has no effect on these. Larger values of $A$ and $N$ give rise to a higher average Bejan number at $\mathrm{Ra}=10^{7}$.

For Rayleigh number in the range of $10^{6}$ to $10^{7}$, the change of trend in $\mathrm{Nu}_{\text {avg, }}, S_{\text {gen, }}$, and $\mathrm{Be}_{\text {avg }}$ with Ra number is caused by the transition from laminar to turbulent flow. The transition of laminar to turbulent flow could be observed in Figure 20. At $\mathrm{Ra}=10^{7}, \mathrm{a}$ secondary flow is formed at the lower part of the cavity. From the isothermal and streamline plots, it can be seen that the secondary flow prevents the primary flow from reaching the lower part of the cavity. Thus, the convective heat transfer is hindered along with the roughness elements and consequently reduces the average Nusselt number. A surge in $\mathrm{Be}_{\text {avg }}$ from $\mathrm{Ra}=10^{6}$ to $10^{7}$ could be explained by comparing the Bejan plots in Figure 
21. There is a notable increase in an area dominated by heat transfer irreversibility at $\mathrm{Ra}=$ $10^{7}$ which gives rise to larger $\mathrm{Be}_{\text {avg }}$ value.

\section{Effect of Nanoparticle Volume Fraction}

Figure 22 illustrates the effects of nanoparticle volume fractions on the average Nusselt number. The results are presented for nanofluids with volume fractions $(\varphi)$ of $0 \%$, $1 \%, 2 \%$, and $4 \%$ at $\operatorname{Re}=1000, \operatorname{Ra}=10^{5}$, and $N=8$ with various values of $A$. Figure 22 shows a linear increase of $\mathrm{Nu}_{\text {avg }}$ with the volume fraction of nanoparticles. It indicates that the addition of nanoparticles enhances the heat transfer rate. The increase of nanoparticle concentration in base fluid augments the effective thermal conductivity, hence, the heat transfer between the roughness elements and nanofluid. The presence of nanoparticles in the fluid enhances the $\mathrm{Nu}_{\text {avg }}$ by approximately $7.3 \%$ at a volume fraction of $4 \%$ at $A=0.10$. The increment in heat transfer rate is a similar disregard of the roughness element amplitude.

The effects of nanoparticle volume fractions $(\varphi)$ on the entropy generation and Bejan number are presented in Figure 23. It is noticed that entropy generation due to heat transfer $\left(S_{g e n, h}\right)$ drops linearly with increasing $\varphi$ values. This is expected as increasing nanoparticle volume fraction increases the effective thermal conductivity which enhances the local heat transfer leading to a lower local temperature gradient, hence, reduces the entropy generation by heat transfer. As observed in Figure 23, higher $\varphi$ decreases the entropy generation due to the fluid friction $\left(S_{g e n, f}\right)$. It is evident from Figure 23 that increasing nanoparticle concentration increases the average Bejan number linearly. For instance, the nanoparticle volume fraction of $4 \%$ enhances the $\mathrm{Be}_{\text {avg }}$ of the fluid by $4 \%$. 


\section{CONCLUSIONS}

A numerical investigation has been performed to study mixed convection of $\mathrm{Al}_{2} \mathrm{O}_{3}-$ water nanofluids in a square lid-driven cavity with a wavy bottom wall, to provide an insight into the enhancement of heat transfer through geometry and medium optimization. The obtained results show that increased amplitude reduces the heat transfer rate, as well as increases the average entropy generation and Bejan number. The roughness elements reduce the heat transfer rate and total entropy generation while increasing the average Bejan number. It is notable that varying amplitude has a higher effect on both the total entropy generation and average Bejan number than that of the roughness elements. Besides, the augmentation of the average Bejan number by varying amplitude and number of roughness elements is more distinct at higher $\operatorname{Re}(\geq 1000)$. Variations of the number and amplitude of roughness elements have a negligible effect on the average Bejan number at $\operatorname{Re}=100$. Moreover, the heat transfer rate and entropy generation increase with the increase of forced convection effect. The rise in Re reduces the average Bejan number as a greater inertial force augments the fluid friction irreversibility. For Rayleigh number $\leq 10^{6}$, the heat transfer rate and total entropy generation increase with the $\mathrm{Ra}$, whereas the average Bejan number and entropy generation due to fluid friction show a decreasing trend. For $\mathrm{Ra}>10^{6}$, a fall in the average Nusselt number, heat transfer, and entropy generation due to the fluid friction are observed. Meanwhile, there is a surge in the average Bejan number. This sudden change in trend is caused by the transition from laminar to turbulent flow. Furthermore, the decay in average Nusselt number and total entropy generation, as well as the surge in the average Bejan number occur at a higher Ra value when roughness 
elements have a higher amplitude whereas a various number of roughness elements has no effect on these. Increasing nanoparticle volume fraction enhances the heat transfer rate while reduces the total entropy generation. It is concluded that the entropy generation due to heat transfer plays a greater role in the enhancement of total entropy generation. The minimum entropy generation could be achieved at low $\operatorname{Ra}$ and low $\operatorname{Re}$ at a fixed $\varphi, N$, and $A$. It is evident from the present study that the addition of small surface feature in a heated surface could be a pathway in minimizing the entropy generation and enhancing the conductive heat transfer instead of using smooth surfaces.

\section{REFERENCES}

[1] Lee, S., Choi, S. U. S., Li, S., and Eastman, J. A., 1999, "Measuring thermal conductivity of fluids containing oxide nanoparticles," Journal of Heat Transfer, 121(2), pp. 280-289.

[2] Selvakumar, P., and Suresh, S., 2012, "Convective performance of CuO/water nanofluid in an electronic heat sink," Experimental Thermal and Fluid Science, 40, pp. 57-63.

[3] Philip, J., and Shima, P. D., 2012, "Thermal properties of nanofluids," Advances in Colloid and Interface Science, 183-184, pp. 30-45.

[4] Borode, A. O., Ahmed, N. A., and Olubambi, P. A., 2019, "Surfactant-aided dispersion of carbon nanomaterials in aqueous solution," Physics of Fluids, 31(7), p. 071301.

[5] Timofeeva, E. V., Yu, W., France, D. M., Singh, D., and Routbort, J. L., 2011, "Base fluid and temperature effects on the heat transfer characteristics of $\mathrm{SiC}$ in ethylene glycol/H2O and $\mathrm{H} 2 \mathrm{O}$ nanofluids," Journal of Applied Physics, 109(1), p. 014914.

[6] Pantzali, M. N., Mouza, A. A., and Paras, S. V., 2009, "Investigating the efficacy of nanofluids as coolants in plate heat exchangers (PHE)," Chem Eng Sci, 64(14), pp. 3290-3300.

[7] Maré, T., Halelfadl, S., Sow, O., Estellé, P., Duret, S., and Bazantay, F., 2011, "Comparison of the thermal performances of two nanofluids at low temperature in a plate heat exchanger," Experimental Thermal and Fluid Science, 35(8), pp. 1535-1543.

[8] Khanafer, K., Vafai, K., and Lightstone, M., 2003, "Buoyancy-driven heat transfer enhancement in a two-dimensional enclosure utilizing nanofluids," International Journal of Heat and Mass Transfer, 46(19), pp. 3639-3653.

[9] Oztop, H. F., and Abu-Nada, E., 2008, "Numerical study of natural convection in partially heated rectangular enclosures filled with nanofluids," International Journal of Heat and Fluid Flow, 29(5), pp. 1326-1336.

[10] Das, P. K., and Mahmud, S., 2003, "Numerical investigation of natural convection inside a wavy enclosure," International Journal of Thermal Sciences, 42(4), pp. 397-406.

[11] Das, P. K., Mahmud, S., Tasnim, S. H., and Islam, A. K. M. S., 2003, "Effect of surface waviness and aspect ratio on heat transfer inside a wavy enclosure," Int. J. Numer. Methods Heat Fluid Flow, 13(8), pp. 1097-1122.

[12] Nayak, R. K., Bhattacharyya, S., and Pop, I., 2015, "Numerical study on mixed convection and entropy generation of $\mathrm{Cu}$-water nanofluid in a differentially heated skewed enclosure," International Journal of Heat and Mass Transfer, 85, pp. 620-634. 
[13] Tasnim, S. H., Mahmud, S., and Das, P. K., 2002, "Effect of aspect ratio and eccentricity on heat transfer from a cylinder in a cavity," Int. J. Numer. Methods Heat Fluid Flow, 12(7), pp. 855-869.

[14] Wang, X.-Q., and Mujumdar, A. S., 2007, "Heat transfer characteristics of nanofluids: a review," International Journal of Thermal Sciences, 46(1), pp. 1-19.

[15] Cho, C.-C., Chen, C.-L., and Chen, C. O.-K., 2012, "Natural convection heat transfer performance in complex-wavy-wall enclosed cavity filled with nanofluid," International Journal of Thermal Sciences, 60, pp. 255-263.

[16] Jou, R.-Y., and Tzeng, S.-C., 2006, "Numerical research of nature convective heat transfer enhancement filled with nanofluids in rectangular enclosures," International Communications in Heat and Mass Transfer, 33(6), pp. 727-736.

[17] Mahmud, S., Das, P. K., and Hyder, N., 2002, "Laminar natural convection around an isothermal square cylinder at different orientations," International Communications in Heat and Mass Transfer, 29(7), pp. 993-1003.

[18] Mahmud, S., Das, P. K., Hyder, N., and Islam, A. K. M. S., 2002, "Free convection in an enclosure with vertical wavy walls," International Journal of Thermal Sciences, 41(5), pp. 440-446.

[19] Ma, Y., Mohebbi, R., Rashidi, M. M., and Yang, Z., 2018, "Study of nanofluid forced convection heat transfer in a bent channel by means of lattice Boltzmann method," Physics of Fluids, 30(3), p. 032001.

[20] Al-Srayyih, B. M., Gao, S., and Hussain, S. H., 2019, "Natural convection flow of a hybrid nanofluid in a square enclosure partially filled with a porous medium using a thermal nonequilibrium model," Physics of Fluids, 31(4), p. 043609.

[21] Bendaraa, A., Charafi, M. M., and Hasnaoui, A., 2019, "Numerical study of natural convection in a differentially heated square cavity filled with nanofluid in the presence of fins attached to walls in different locations," Physics of Fluids, 31(5), p. 052003.

[22] Basak, T., Roy, S., Sharma, P. K., and Pop, I., 2009, "Analysis of mixed convection flows within a square cavity with uniform and non-uniform heating of bottom wall," International Journal of Thermal Sciences, 48(5), pp. 891-912.

[23] Buongiorno, J., 2006, "Convective transport in nanofluids," Journal of Heat Transfer, 128(3), pp. 240-250.

[24] Tiwari, R. K., and Das, M. K., 2007, "Heat transfer augmentation in a two-sided lid-driven differentially heated square cavity utilizing nanofluids," International Journal of Heat and Mass Transfer, 50(9-10), pp. 2002-2018.

[25] Nemati, H., Farhadi, M., Sedighi, K., Fattahi, E., and Darzi, A. A. R., 2010, "Lattice Boltzmann simulation of nanofluid in lid-driven cavity," International Communications in Heat and Mass Transfer, 37(10), pp. 1528-1534.

[26] Talebi, F., Mahmoudi, A. H., and Shahi, M., 2010, "Numerical study of mixed convection flows in a square lid-driven cavity utilizing nanofluid," International Communications in Heat and Mass Transfer, 37(1), pp. 79-90.

[27] Mansour, M. A., Mohamed, R. A., Abd-Elaziz, M. M., and Ahmed, S. E., 2010, "Numerical simulation of mixed convection flows in a square lid-driven cavity partially heated from below using nanofluid," International Communications in Heat and Mass Transfer, 37(10), pp. 1504-1512.

[28] Nayak, R. K., Bhattacharyya, S., and Pop, I., 2015, "Numerical study on mixed convection and entropy generation of a nanofluid in a lid-driven square enclosure," Journal of Heat Transfer, 138(1), pp. 012503-012503-012511.

[29] Hussain, S., Mehmood, K., and Sagheer, M., 2016, "MHD mixed convection and entropy generation of water-alumina nanofluid flow in a double lid driven cavity with discrete heating," Journal of Magnetism and Magnetic Materials, 419, pp. 140-155.

[30] Cong, R., Ozaki, Y., Machado, B. D. S., and Das, P. K., 2018, "Constructal design of a rectangular fin in a mixed convective confined environment," Inventions, 3(2), p. 27. 
[31] Sourtiji, E., Gorji-Bandpy, M., Ganji, D. D., and Hosseinizadeh, S. F., 2014, "Numerical analysis of mixed convection heat transfer of $\mathrm{Al}_{2} \mathrm{O}_{3}$-water nanofluid in a ventilated cavity considering different positions of the outlet port," Powder Technology, 262, pp. 71-81.

[32] Al-Amiri, A., Khanafer, K., Bull, J., and Pop, I., 2007, "Effect of sinusoidal wavy bottom surface on mixed convection heat transfer in a lid-driven cavity," International Journal of Heat and Mass Transfer, 50(9-10), pp. 1771-1780.

[33] Bejan, A., 1982, Entropy generation through heat and fluid flow, Wiley, New York.

[34] Bejan, A., 2004, Convection heat transfer, Wiley, New York.

[35] Mahmud, S., and Islam, A. K. M. S., 2003, "Laminar free convection and entropy generation inside an inclined wavy enclosure," International Journal of Thermal Sciences, 42(11), pp. 1003-1012. [36] Mahmud, S., and Fraser, R. A., 2004, "Free convection and entropy generation inside a vertical inphase wavy cavity," International Communications in Heat and Mass Transfer, 31(4), pp. 455-466.

[37] Magherbi, M., Abbassi, H., and Ben Brahim, A., 2003, "Entropy generation at the onset of natural convection," International Journal of Heat and Mass Transfer, 46(18), pp. 3441-3450.

[38] Cho, C.-C., 2014, "Heat transfer and entropy generation of natural convection in nanofluid-filled square cavity with partially-heated wavy surface," International Journal of Heat and Mass Transfer, 77, pp. 818-827.

[39] Oliveski, R. D. C., Macagnan, M. H., and Copetti, J. B., 2009, "Entropy generation and natural convection in rectangular cavities," Applied Thermal Engineering, 29(8-9), pp. 1417-1425.

[40] Khorasanizadeh, H., Nikfar, M., and Amani, J., 2013, "Entropy generation of Cu-water nanofluid mixed convection in a cavity," European Journal of Mechanics - B/Fluids, 37, pp. 143-152.

[41] Mamourian, M., Milani Shirvan, K., Ellahi, R., and Rahimi, A. B., 2016, "Optimization of mixed convection heat transfer with entropy generation in a wavy surface square lid-driven cavity by means of Taguchi approach," International Journal of Heat and Mass Transfer, 102, pp. 544-554.

[42] Ting, K., Mozumder, A. K., and Das, P. K., 2018, "Heat transfer and entropy generation of mixed convection in nanofluid inside a rough cavity," AIP Conference Proceedings, 1980(1), p. 050005.

[43] Das, P. K., Li, X., and Liu, Z. S., 2007, "Analytical approach to polymer electrolyte membrane fuel cell performance and optimization," J. Electroanal. Chem., 604(2), pp. 72-90.

[44] Das, P. K., Li, X., and Liu, Z. S., 2010, "Effective transport coefficients in PEM fuel cell catalyst and gas diffusion layers: beyond Bruggeman approximation," Appl. Energ., 87(9), pp. 2785-2796.

[45] Das, P. K., Li, X., Xie, Z., and Liu, Z. S., 2011, "Effects of catalyst layer structure and wettability on liquid water transport in polymer electrolyte membrane fuel cell," Int J Energ Res, 35(15), pp. 13251339.

[46] Weber, A. Z., Borup, R. L., Darling, R. M., Das, P. K., Dursch, T. J., Gu, W. B., Harvey, D., Kusoglu, A., Litster, S., Mench, M. M., Mukundan, R., Owejan, J. P., Pharoah, J. G., Secanell, M., and Zenyuk, I. V., 2014, "A critical review of modeling transport phenomena in polymer-electrolyte fuel cells," J Electrochem Soc, 161(12), pp. F1254-F1299.

[47] Xing, L., Shi, W., Su, H., Xu, Q., Das, P. K., Mao, B., and Scott, K., 2019, "Membrane electrode assemblies for PEM fuel cells: A review of functional graded design and optimization," Energy, 177, pp. 445-464.

[48] Xing, L., Shi, W. D., Das, P. K., and Scott, K., 2017, "Inhomogeneous distribution of platinum and ionomer in the porous cathode to maximize the performance of a PEM fuel cell," Aiche J, 63(11), pp. 4895-4910.

[49] Xing, L., Wang, Y., Das, P. K., Scott, K., and Shi, W. D., 2018, "Homogenization of current density of PEM fuel cells by in-plane graded distributions of platinum loading and GDL porosity," Chem Eng Sci, 192, pp. 699-713.

[50] Zenyuk, I. V., Das, P. K., and Weber, A. Z., 2016, "Understanding impacts of catalyst-layer thickness on fuel-cell performance via mathematical modeling," J Electrochem Soc, 163(7), pp. F691F703.

[51] Brinkman, H. C., 1952, "The viscosity of concentrated suspensions and solutions," The Journal of Chemical Physics, 20(4), pp. 571-571. 
[52] Garnett, J. C. M., 1904, "Colours in metal glasses and in metallic films," Philosophical Transactions of the Royal Society of London. Series A, Containing Papers of a Mathematical or Physical Character, 203(359-371), pp. 385-420.

[53] Dixit, H. N., and Babu, V., 2006, "Simulation of high Rayleigh number natural convection in a square cavity using the lattice Boltzmann method," International Journal of Heat and Mass Transfer, 49(3-4), pp. 727-739.

[54] De Vahl Davis, G., 1983, "Natural convection of air in a square cavity: A bench mark numerical solution," International Journal for Numerical Methods in Fluids, 3(3), pp. 249-264.

[55] Ilis, G. G., Mobedi, M., and Sunden, B., 2008, "Effect of aspect ratio on entropy generation in a rectangular cavity with differentially heated vertical walls," International Communications in Heat and Mass Transfer, 35(6), pp. 696-703.

[56] Parlatan, Y., Todreas, N. E., and Driscoll, M. J., 1996, "Buoyancy and property variation effects in turbulent mixed convection of water in vertical tubes," J Heat Trans-T Asme, 118(2), pp. 381-387.

[57] Inagaki, T., 1996, "The criterion for turbulent combined forced and natural convection in a vertical flow system," J Heat Trans-T Asme, 118(1), pp. 213-215.

[58] Symolon, P., Neuhaus, W., and Odell, R., 2004, "Mixed Convection Heat Transfer Experiments in Smooth and Rough Verticla Tubes," Transactions of the American Nuclear Society, 92.

[59] Wang, J. L., Li, J. K., and Jackson, J. D., 2004, "A study of the influence of buoyancy on turbulent flow in a vertical plane passage," Int J Heat Fluid Fl, 25(3), pp. 420-430. 


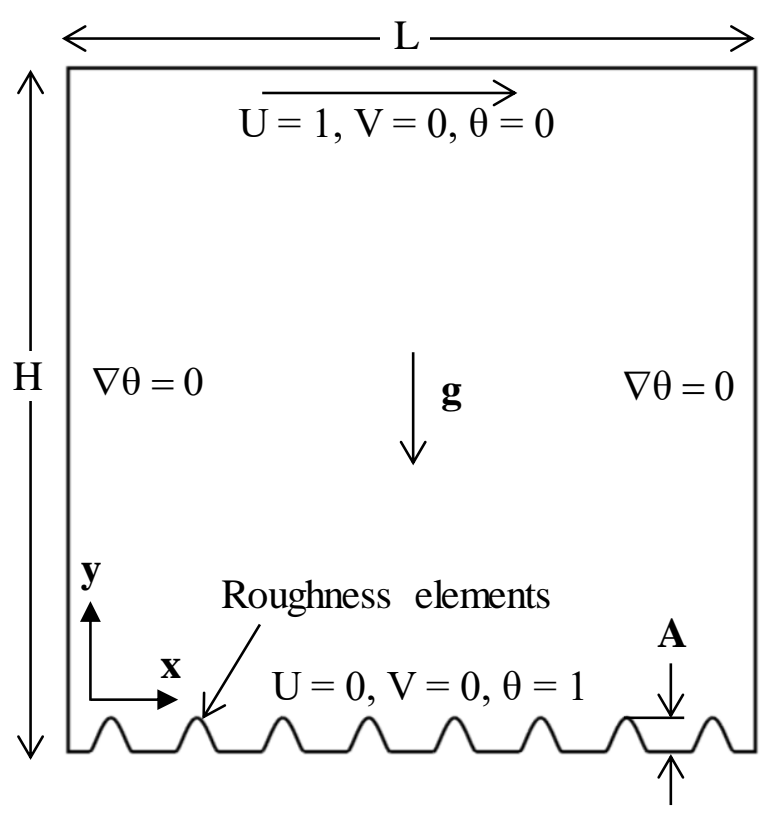

Figure 1. Schematic diagram of the geometry with roughness elements. 


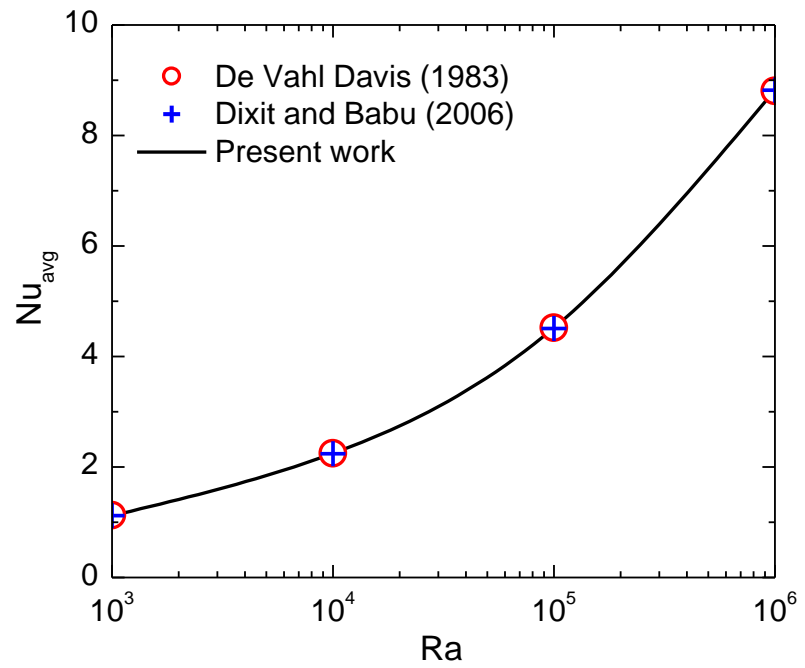

Figure 2. Comparison of average Nusselt numbers with published data [53, 54]. 

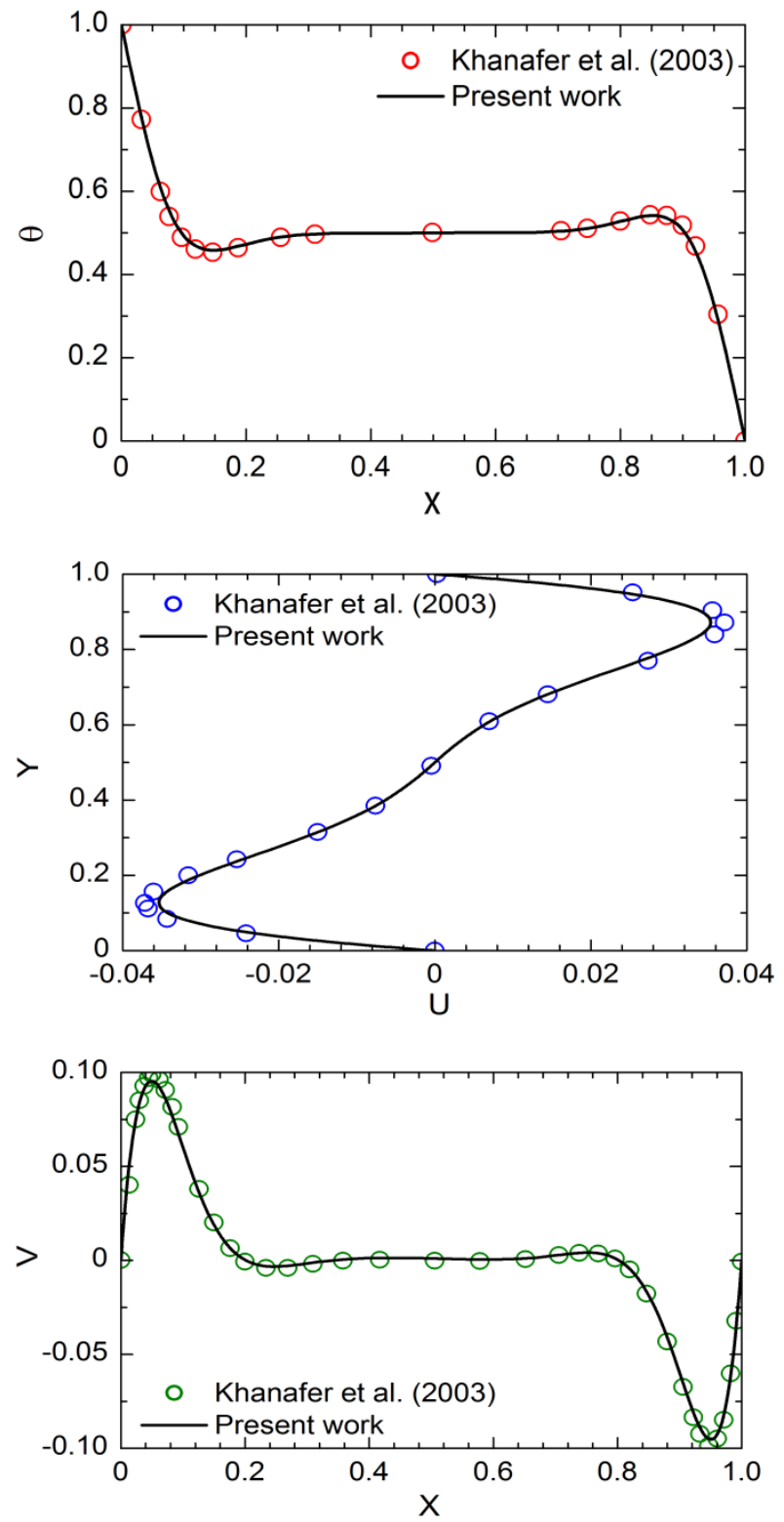

Figure 3. Comparison of the temperature and velocity profiles at mid-sections of the cavity for $\mathrm{Gr}=10^{5}, \operatorname{Pr}=6.2$, and $\varphi=5 \%$ with published data [8]. 


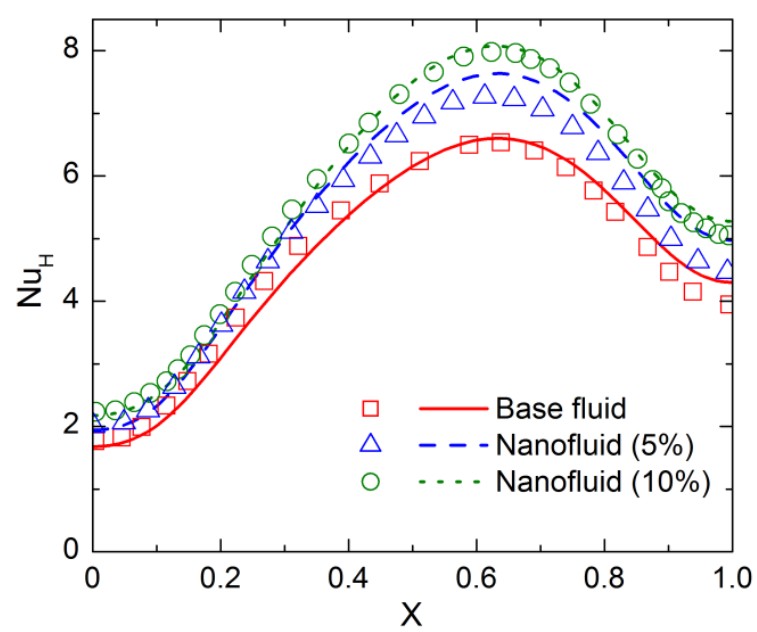

Figure 4. Comparison of local Nusselt number distributions along the bottom wall of the cavity for $\mathrm{Re}=100$ and $\mathrm{Gr}=10^{3}$, where the lines represent the present modeling results and the symbols are from the literature [28]. 


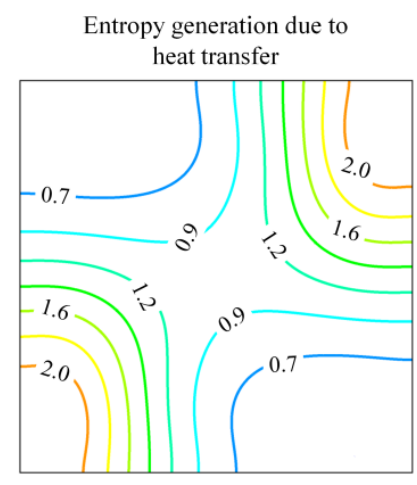

Entropy generation due to

fluid friction
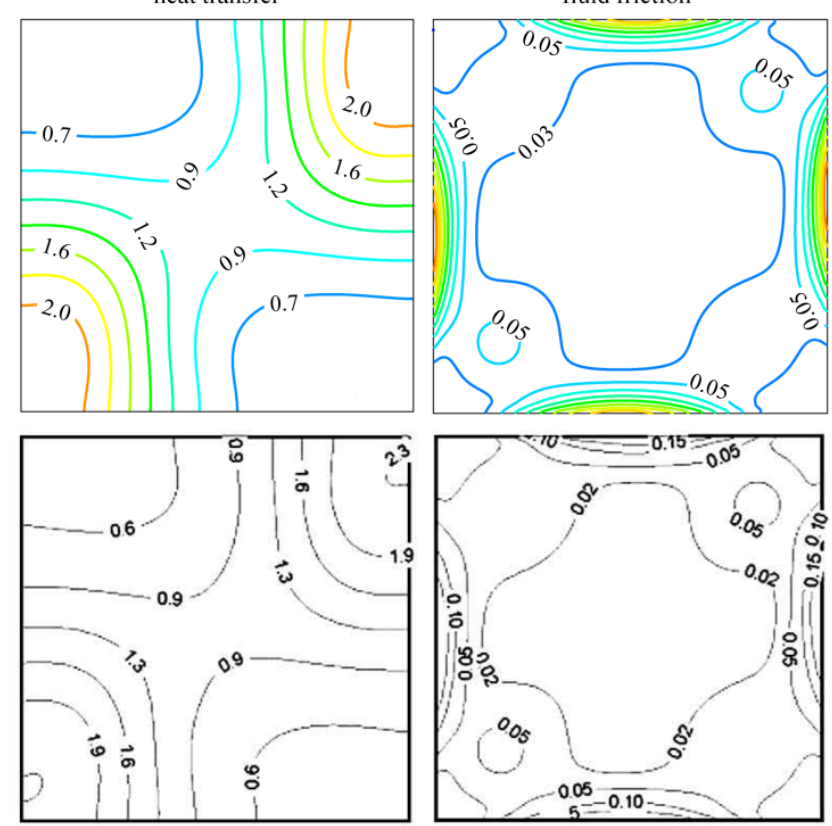

Figure 5. Comparison of local entropy generation contours due to heat transfer (left figure) and fluid friction (right figure) for natural convection of air. The top two figures show the present modeling results, while the bottom two figures show the literature data [55]. 

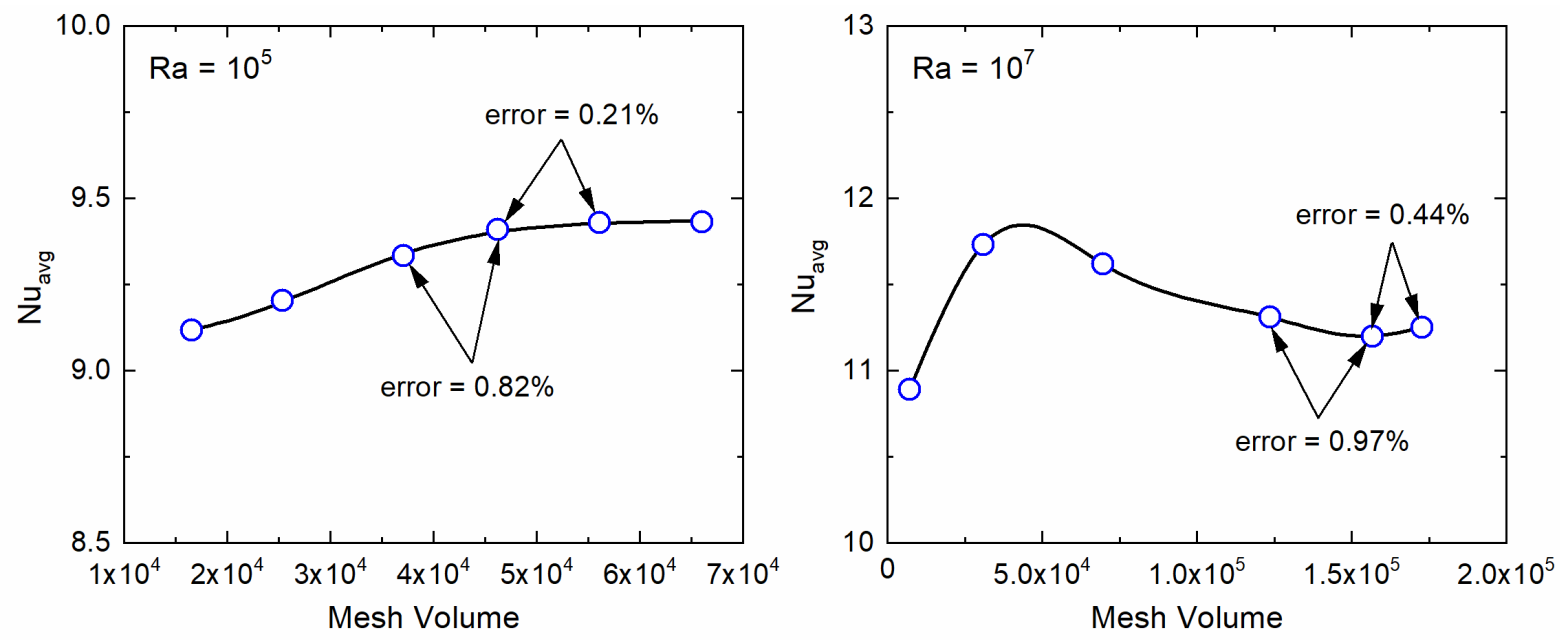

Figure 6. Mesh independence test. 


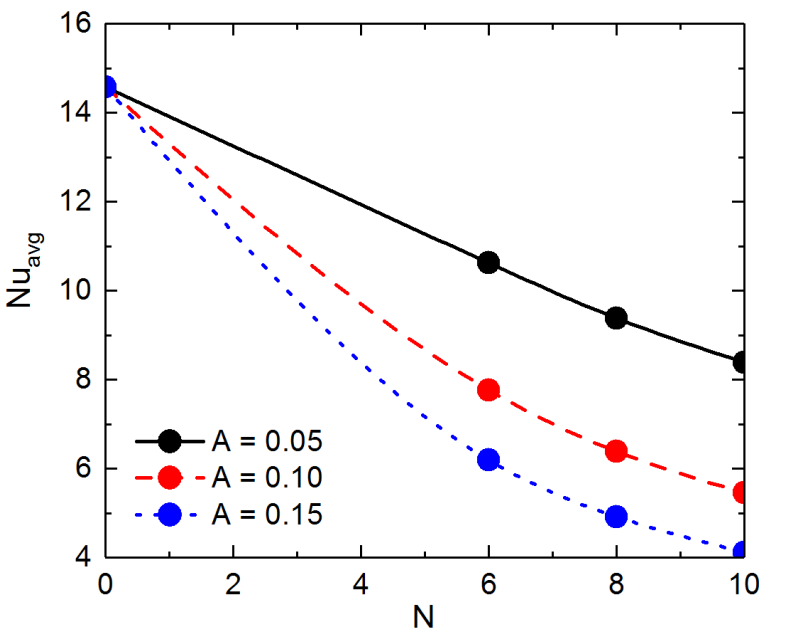

Figure 7. Effects of $A$ and $N$ on $\mathrm{Nu}_{\text {avg }}$ at $\varphi=1 \%, \mathrm{Re}=1000$, and $\mathrm{Ra}=10^{5}$. Here the symbols are the computed data and the lines in the figure are guides for the eye. 


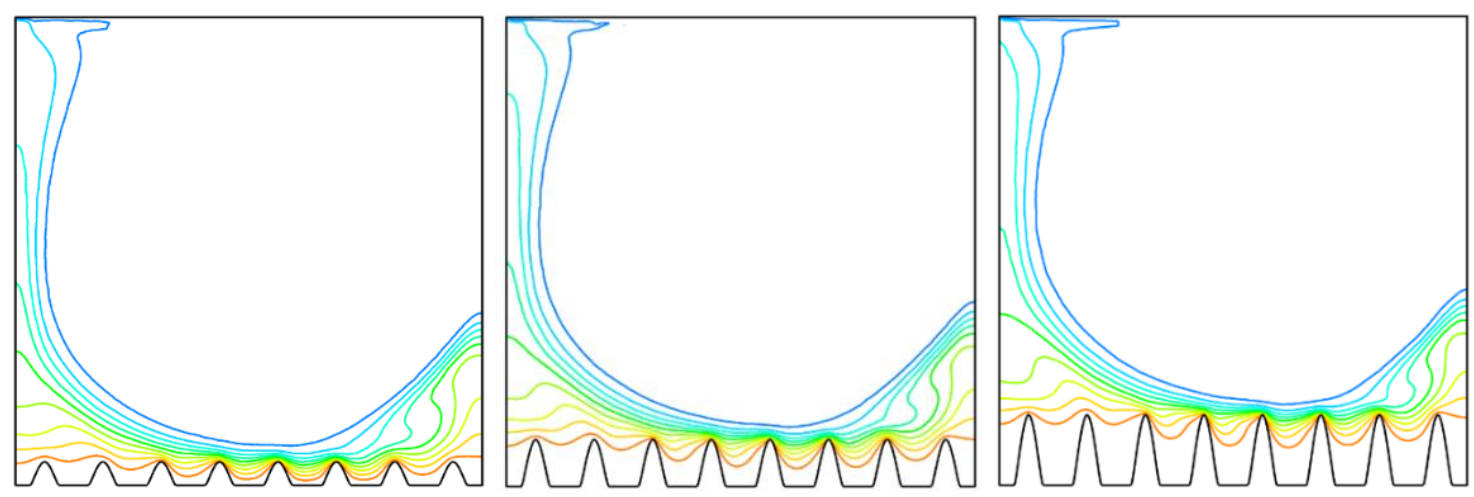

Figure 8 . Isotherms of $1 \% \mathrm{Al}_{2} \mathrm{O}_{3}$-water nanofluid at different amplitudes, $A=0.05,0.10$, and 0.15 (left to right). 


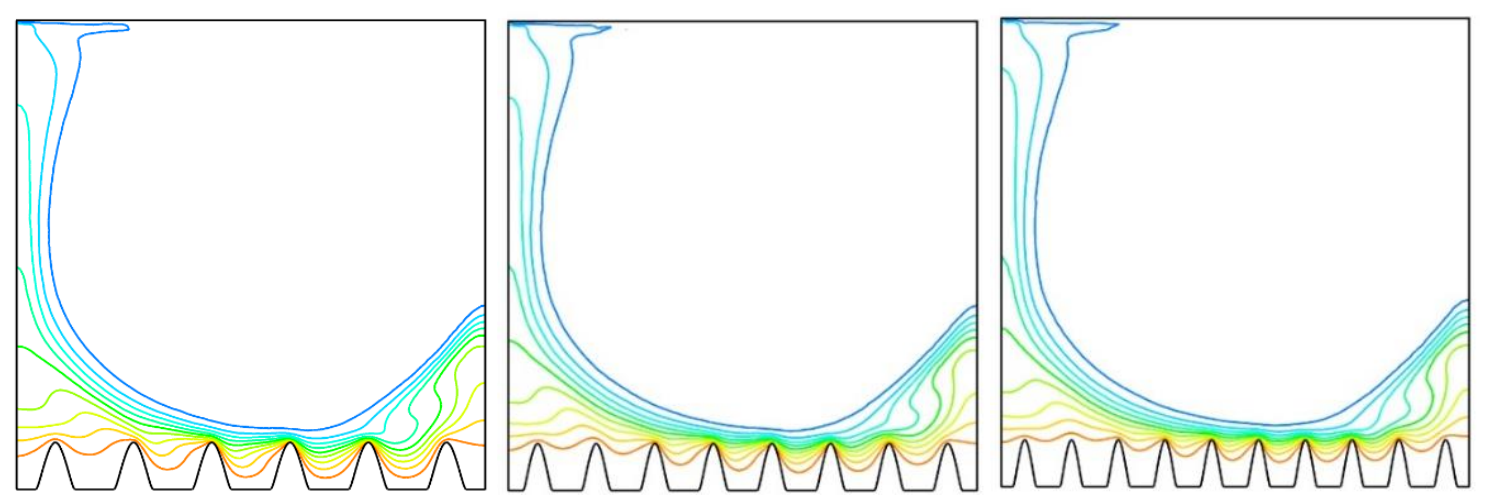

Figure 9. Isotherms of $1 \% \mathrm{Al}_{2} \mathrm{O}_{3}$-water nanofluid at different numbers of roughness elements, $N=6,8$, and 10 (left to right). 

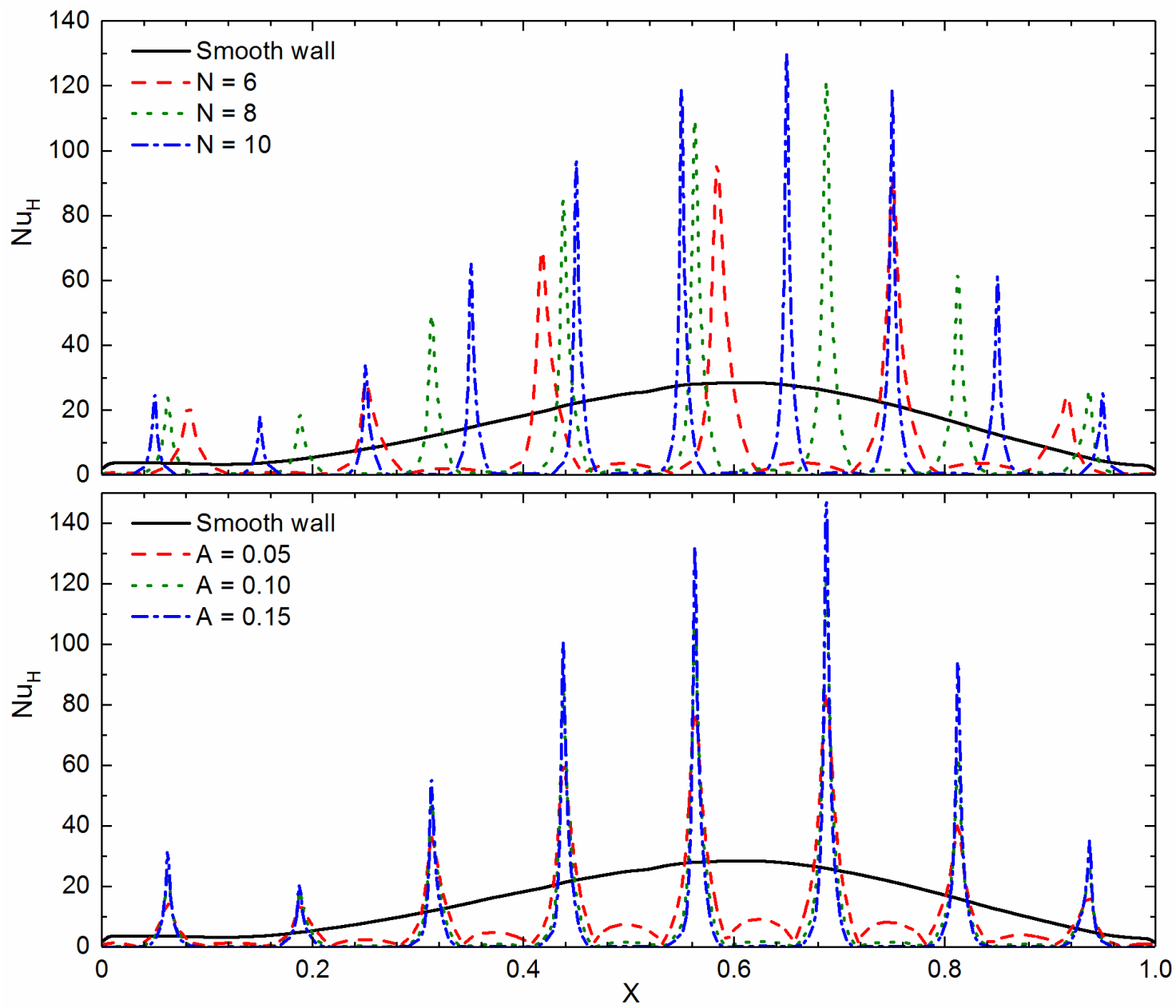

Figure 10. Local heat flux distributions along with the roughness elements for different values of $N$ and $A$. 

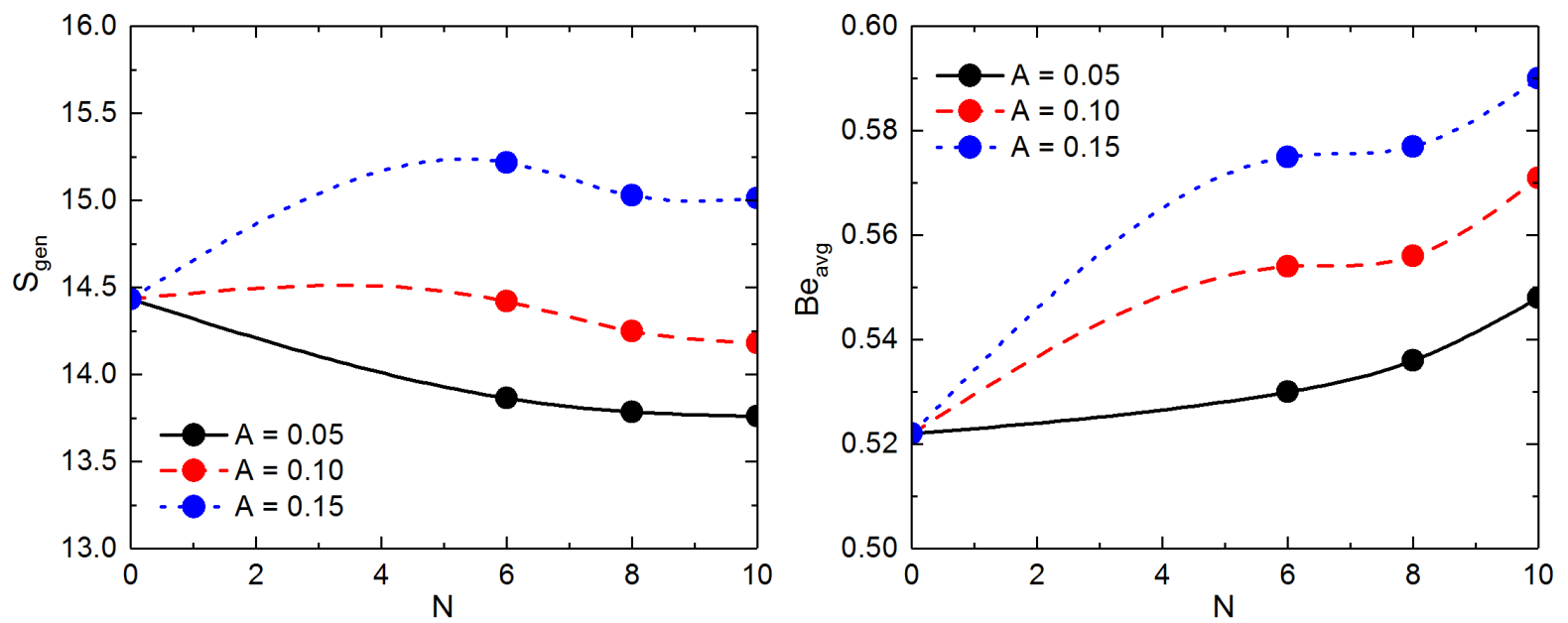

Figure 11. Effects of $N$ and $A$ on $S_{\text {gen }}$ and $B e_{\text {avg }}$ at $\varphi=1 \%, \operatorname{Re}=1000$, and $\operatorname{Ra}=10^{5}$. 


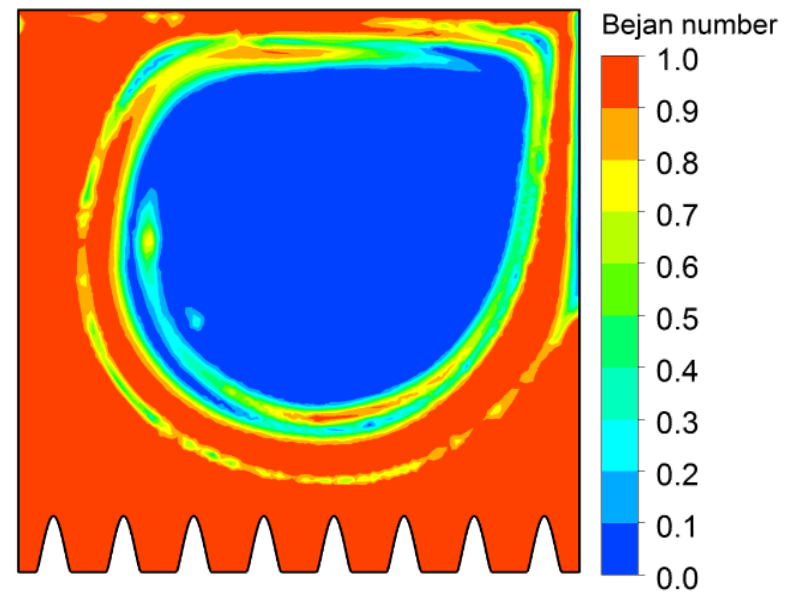

Figure 12. Bejan plot for $1 \% \mathrm{Al}_{2} \mathrm{O}_{3}$-water nanofluid at $N=8, A=0.10, \mathrm{Re}=1000$, and $\mathrm{Ra}=10^{5}$. 

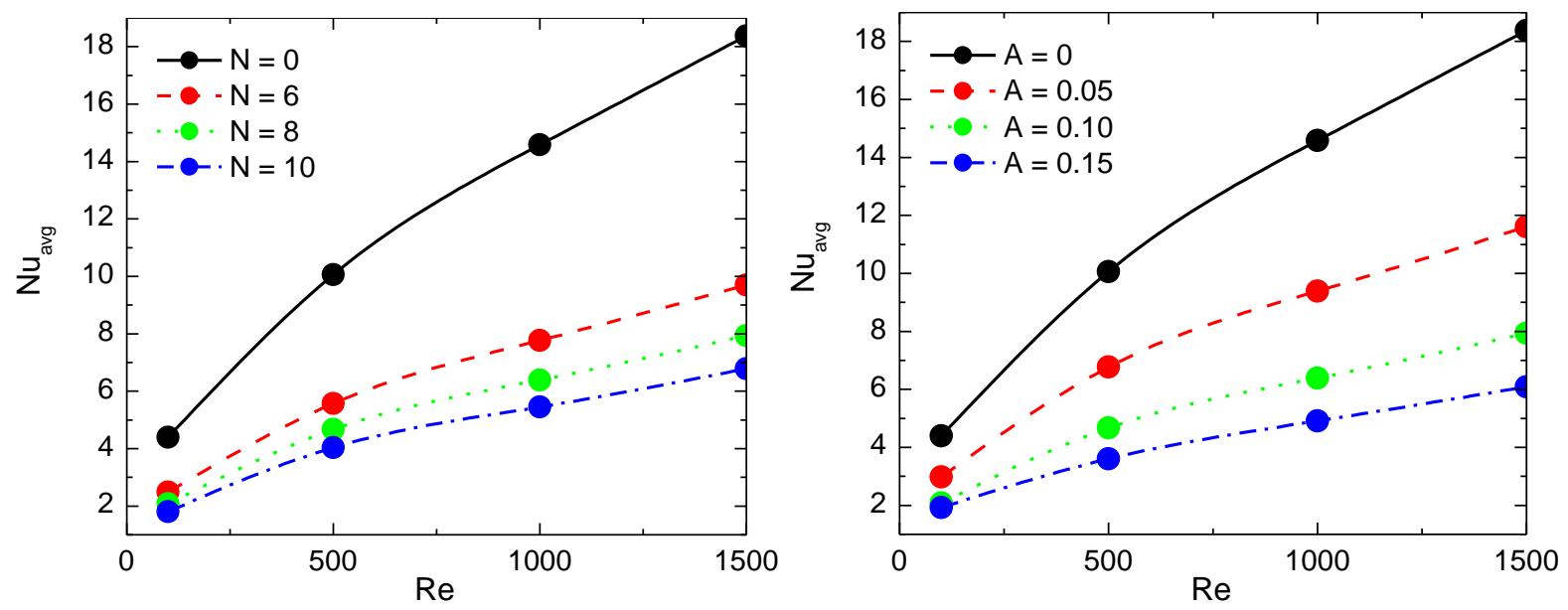

Figure 13. Effects of Re on $\mathrm{Nu}_{\text {avg }}$ for different values of $N$ and $A$ at $\varphi=1 \%$ and $\mathrm{Ra}=10^{5}$. 

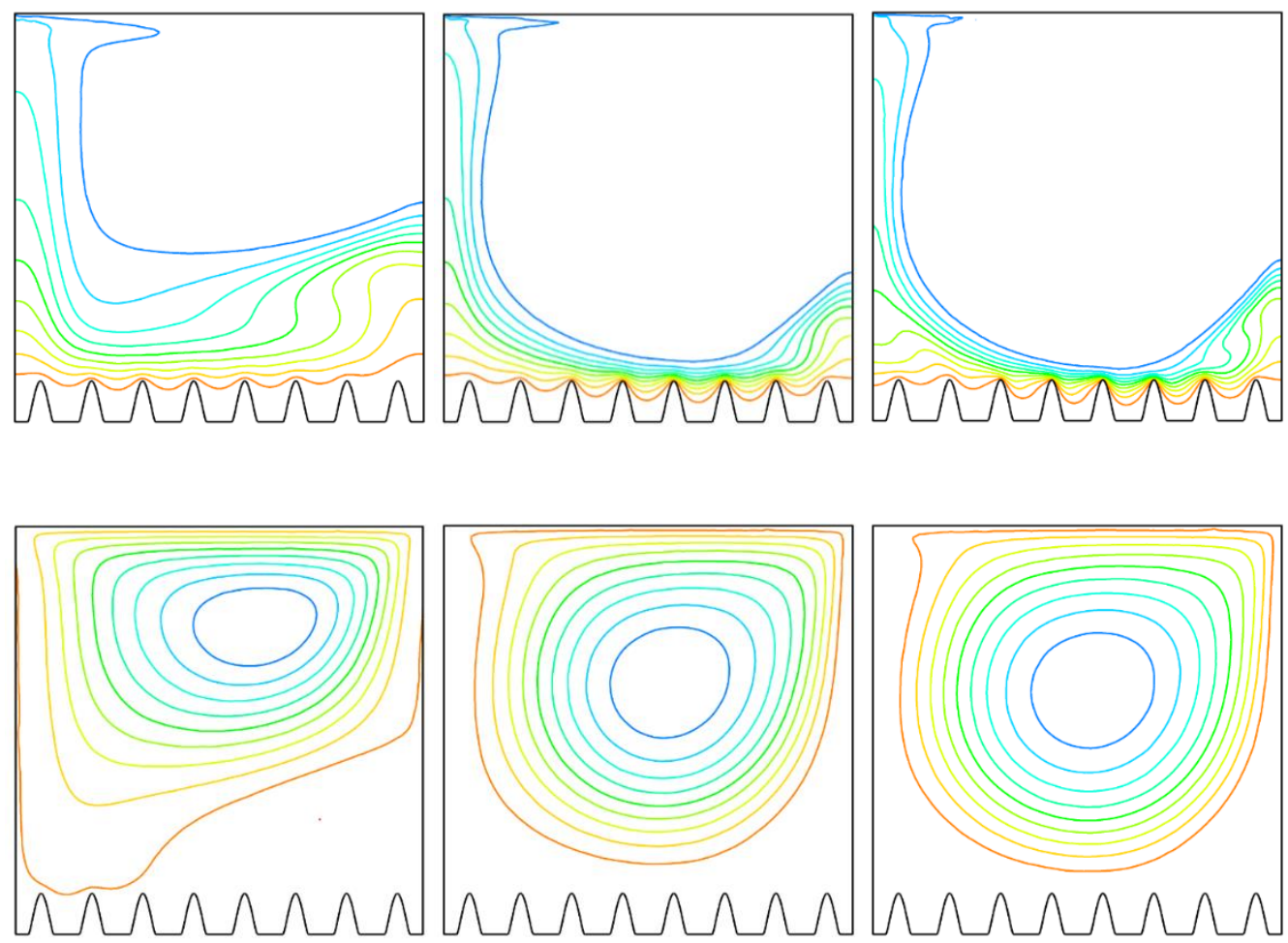

Figure 14. Isotherms (top) and streamlines (bottom) for $\operatorname{Re}=100,500$, and 1000 (left to right) at $\varphi=1 \%, \mathrm{Ra}=10^{5}, N=8$, and $A=0.10$. Part of the figure is reprinted from Ref. [42], with the permission of AIP Publishing. 

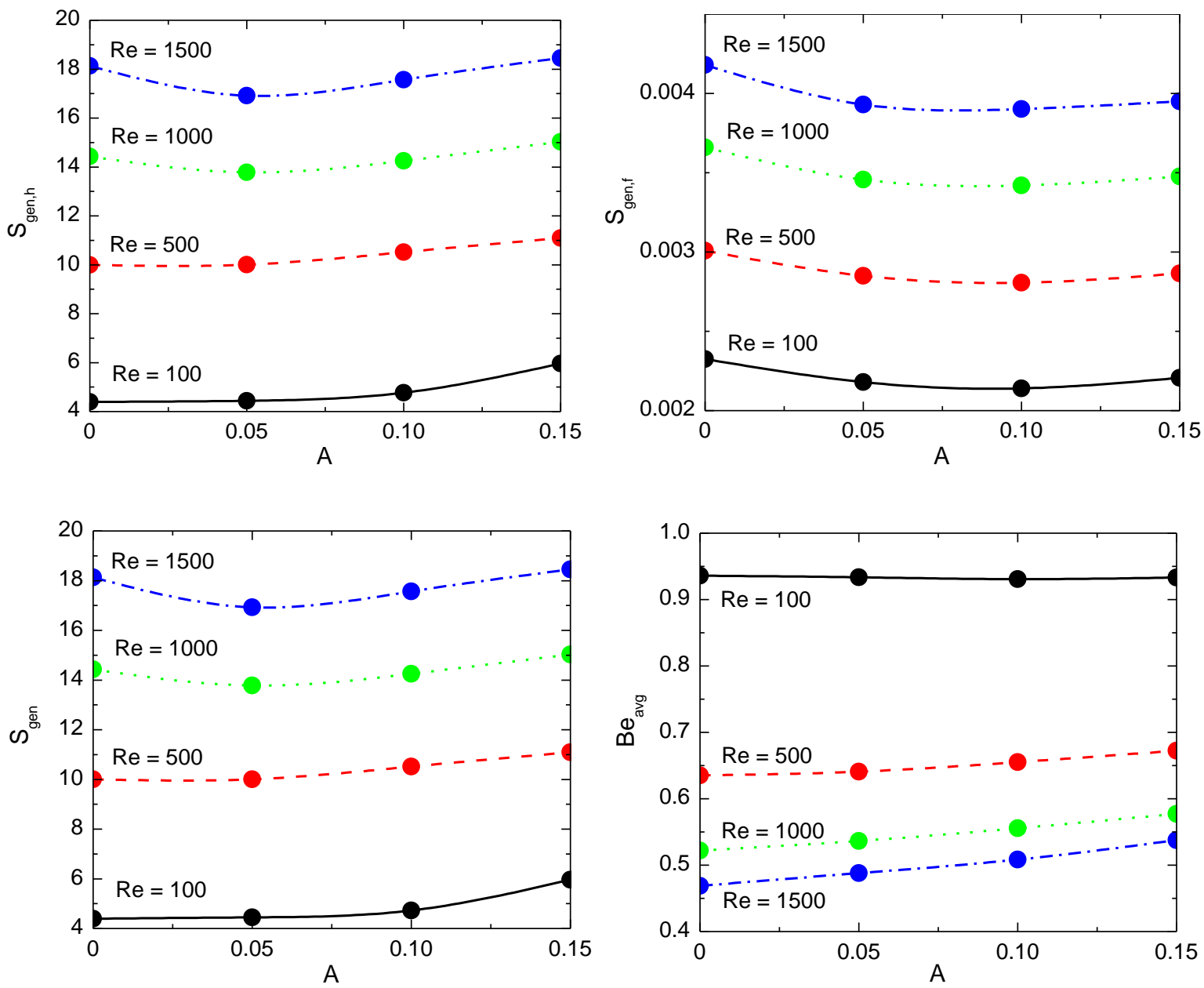

Figure 15. Effects of Re on $S_{g e n, h}, S_{g e n, f}, S_{g e n}$, and Be $e_{\text {avg }}$ as a function of $A$ for $\varphi=1 \%, N=8$, and $\mathrm{Ra}=10^{5}$. 

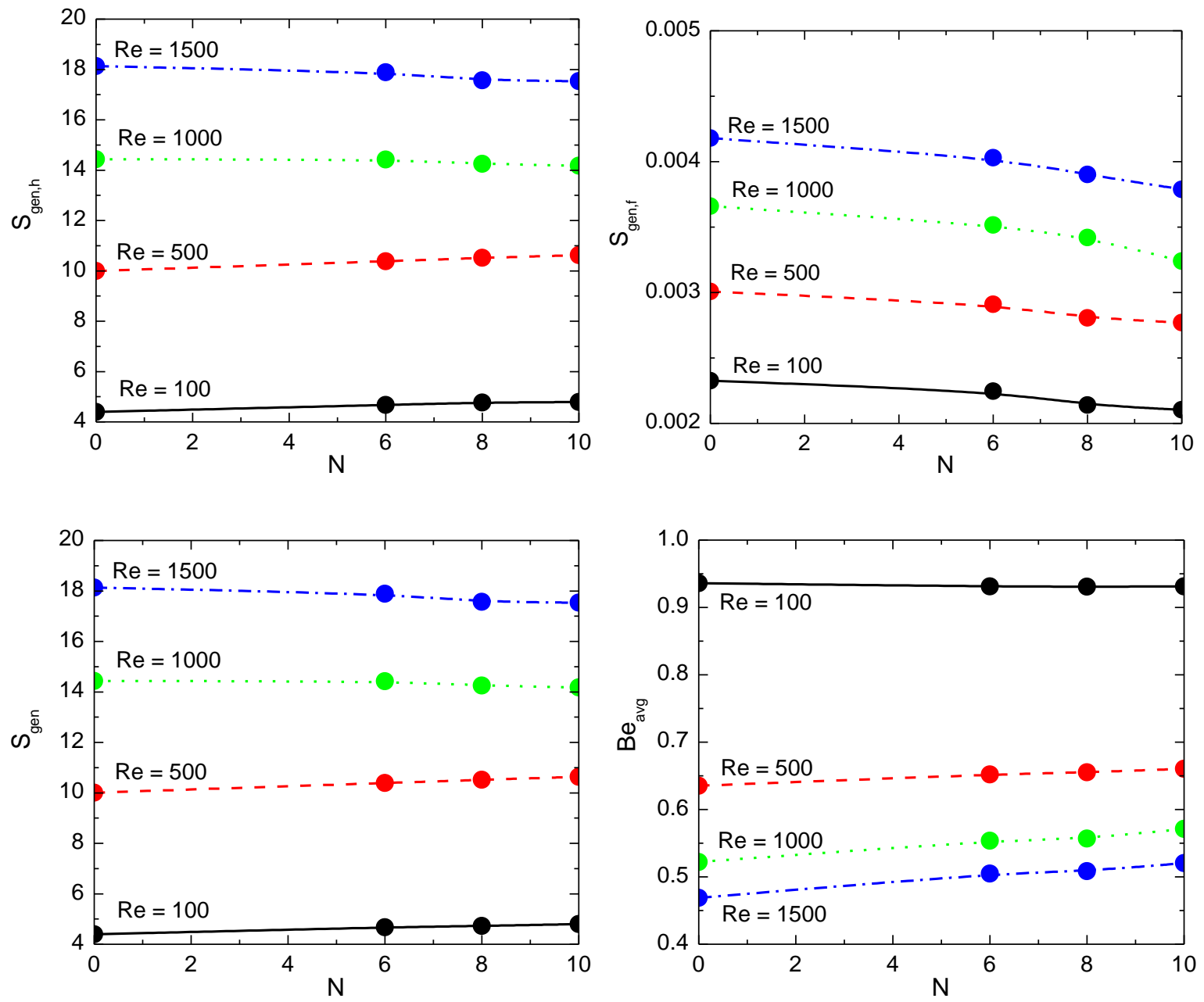

Figure 16. Effects of Re on $S_{g e n, h}, S_{g e n, f}, S_{g e n}$, and Be $e_{\text {avg }}$ for different values of $N$ at $\varphi=1 \%, \operatorname{Re}=$ 1000 , and $A=0.10$. 

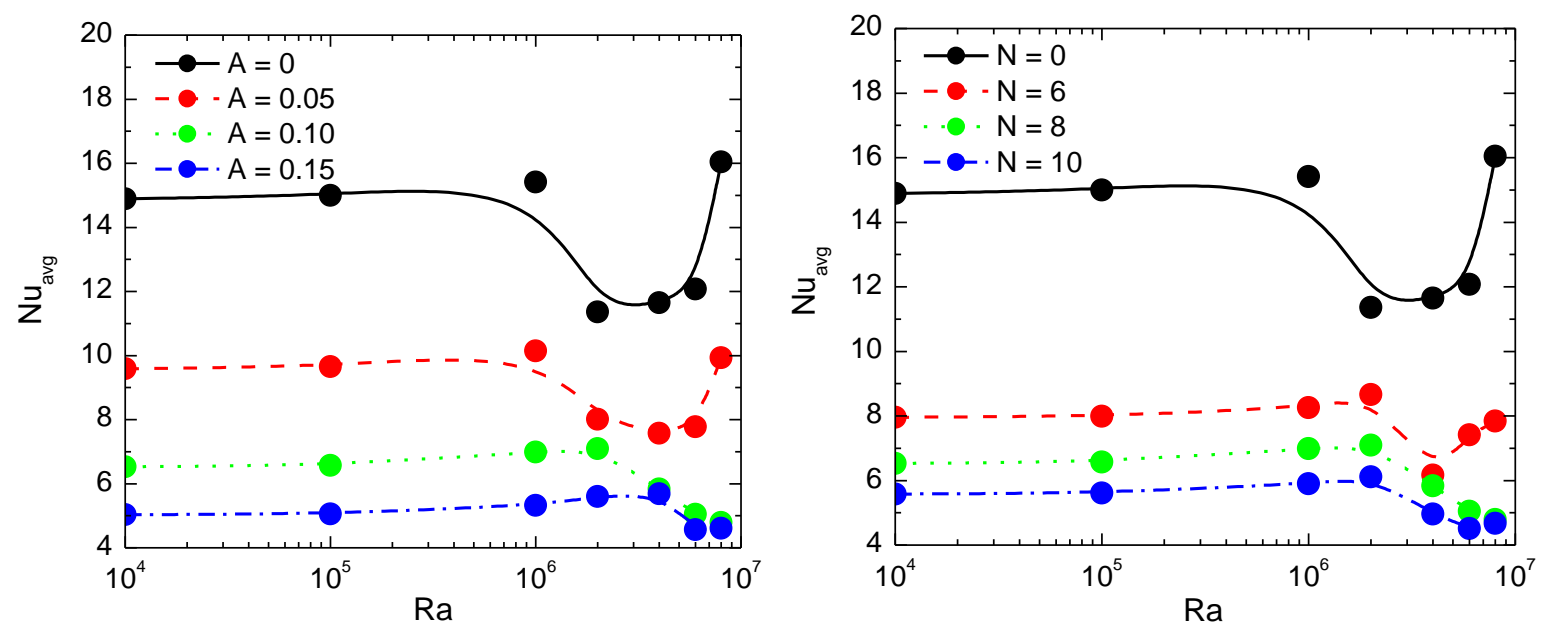

Figure 17. Effects of $\mathrm{Ra}$ on $\mathrm{Nu}_{\text {avg }}$ for different values of $A$ and $N$ at $\varphi=1 \%$ and $\operatorname{Re}=1000$, where the symbols show numerical data and the lines show the B-spline fits. 

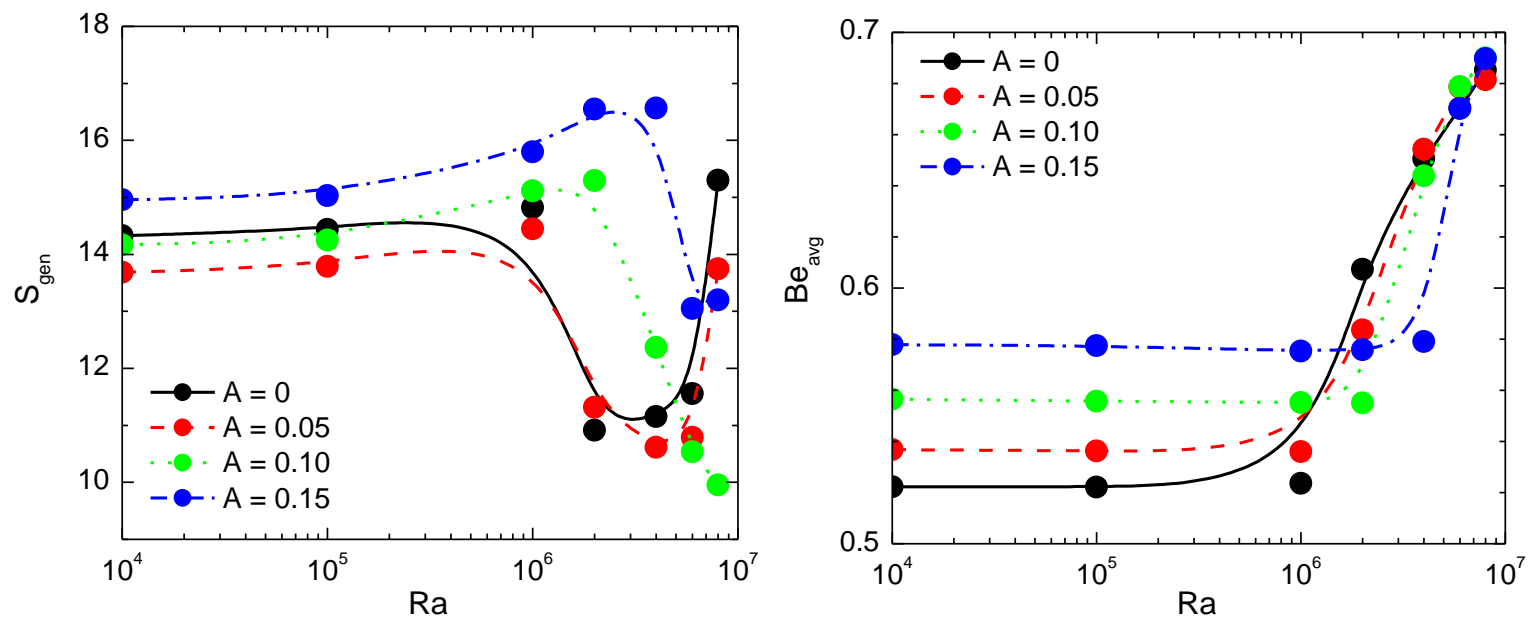

Figure 18. Effects of $\operatorname{Ra}$ on $S_{g e n}$ and $B e_{\text {avg }}$ for various values of $A$ at $\varphi=1 \%$ and $\operatorname{Re}=1000$, where the symbols show numerical data and the lines show B-spline fits. 

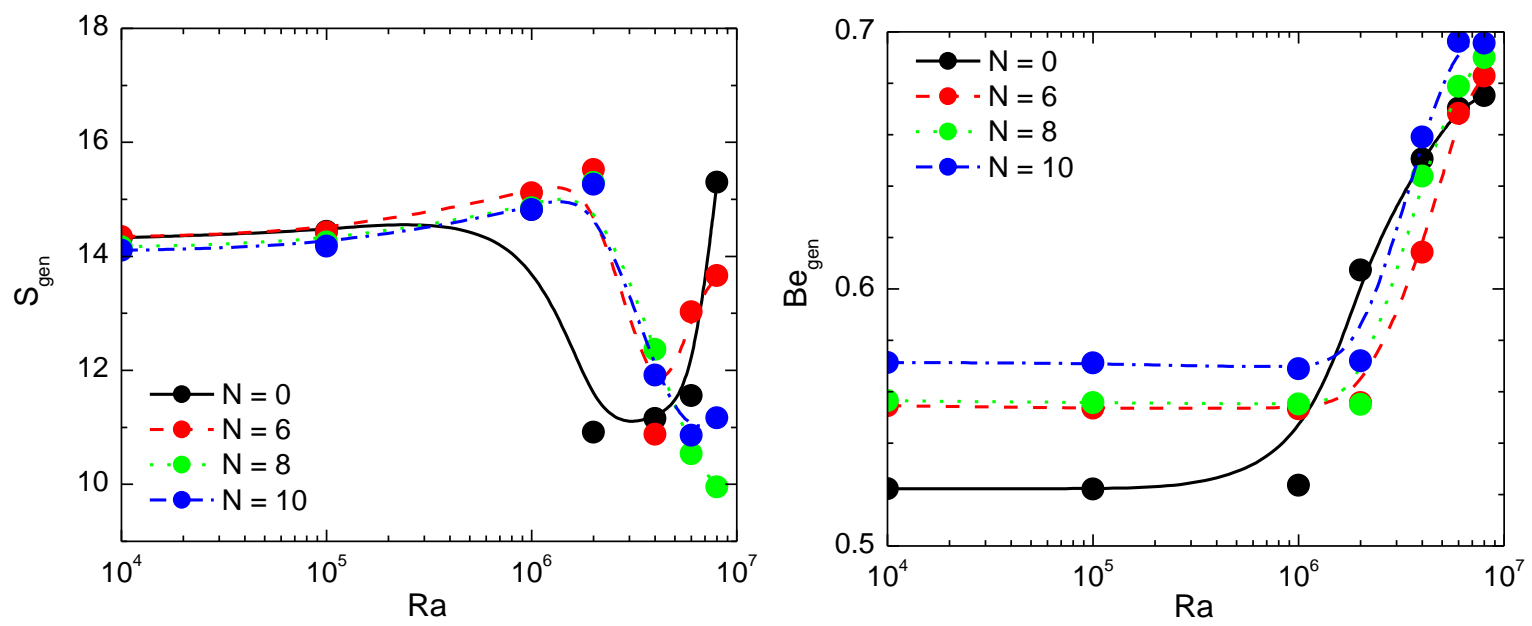

Figure 19. Effects of $\operatorname{Ra}$ on $S_{g e n}$ and Be $e_{\text {avg }}$ for various values of $N$ at $\varphi=1 \%$ and $\operatorname{Re}=1000$, where the symbols show numerical data and the lines show B-spline fits. 

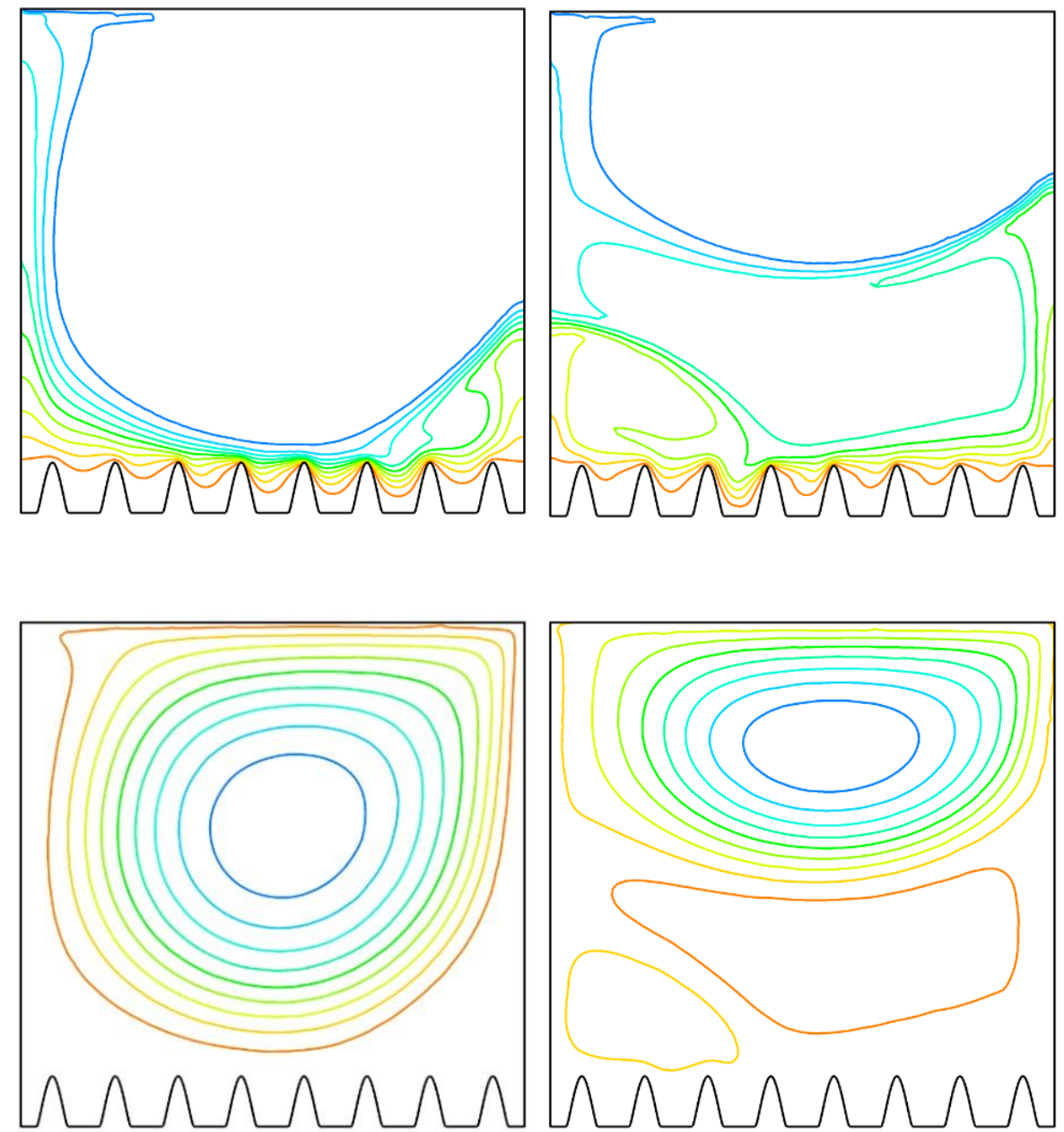

Figure 20. Isotherms (top) and streamlines (bottom) for $\mathrm{Ra}=10^{6}$ (left) and $10^{7}$ (right) at $\varphi=$ $1 \%, \operatorname{Re}=1000, N=8$, and $A=0.10$. 


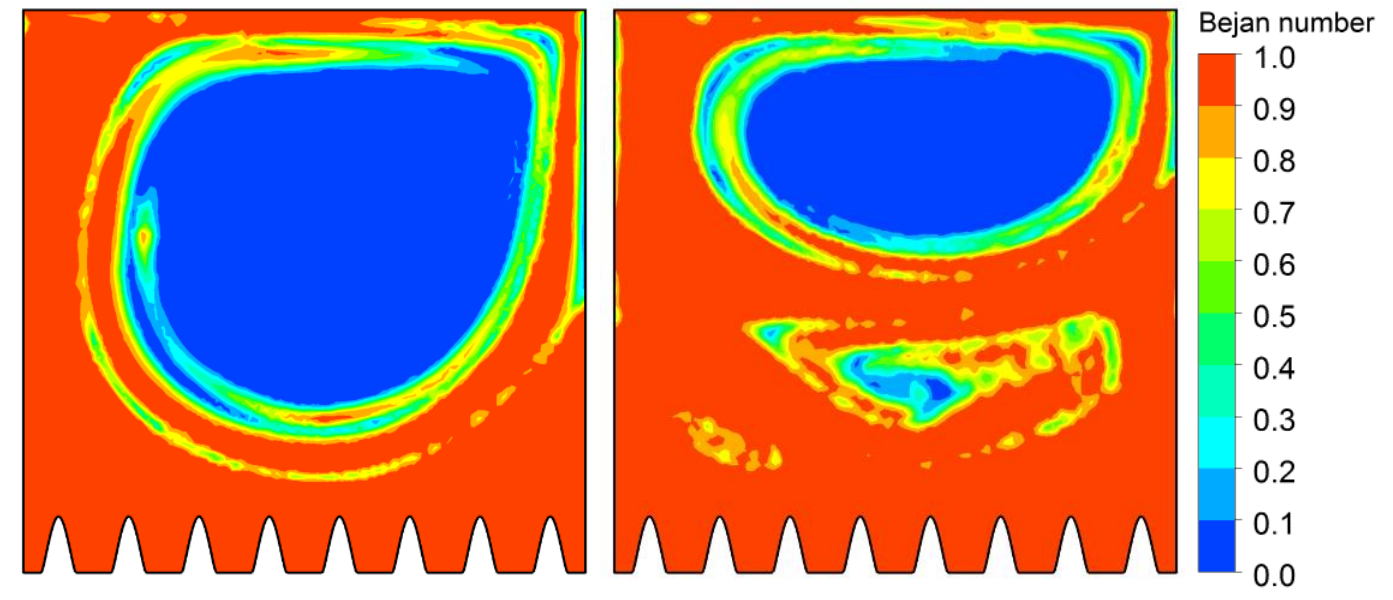

Figure 21. Bejan plots for $\mathrm{Ra}=10^{6}$ (left) and $10^{7}$ (right) at $\mathrm{Re}=1000, N=8$, and $A=0.10$. 


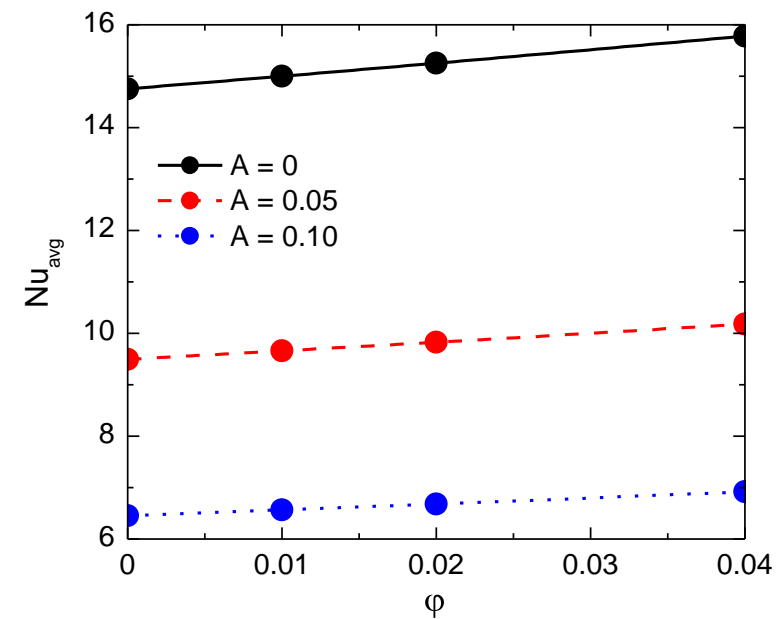

Figure 22. Effects of $\varphi$ on $\mathrm{Nu}_{\text {avg }}$ for different values of $A$ when $N=8, \operatorname{Re}=1000$, and $\mathrm{Ra}=10^{5}$. 

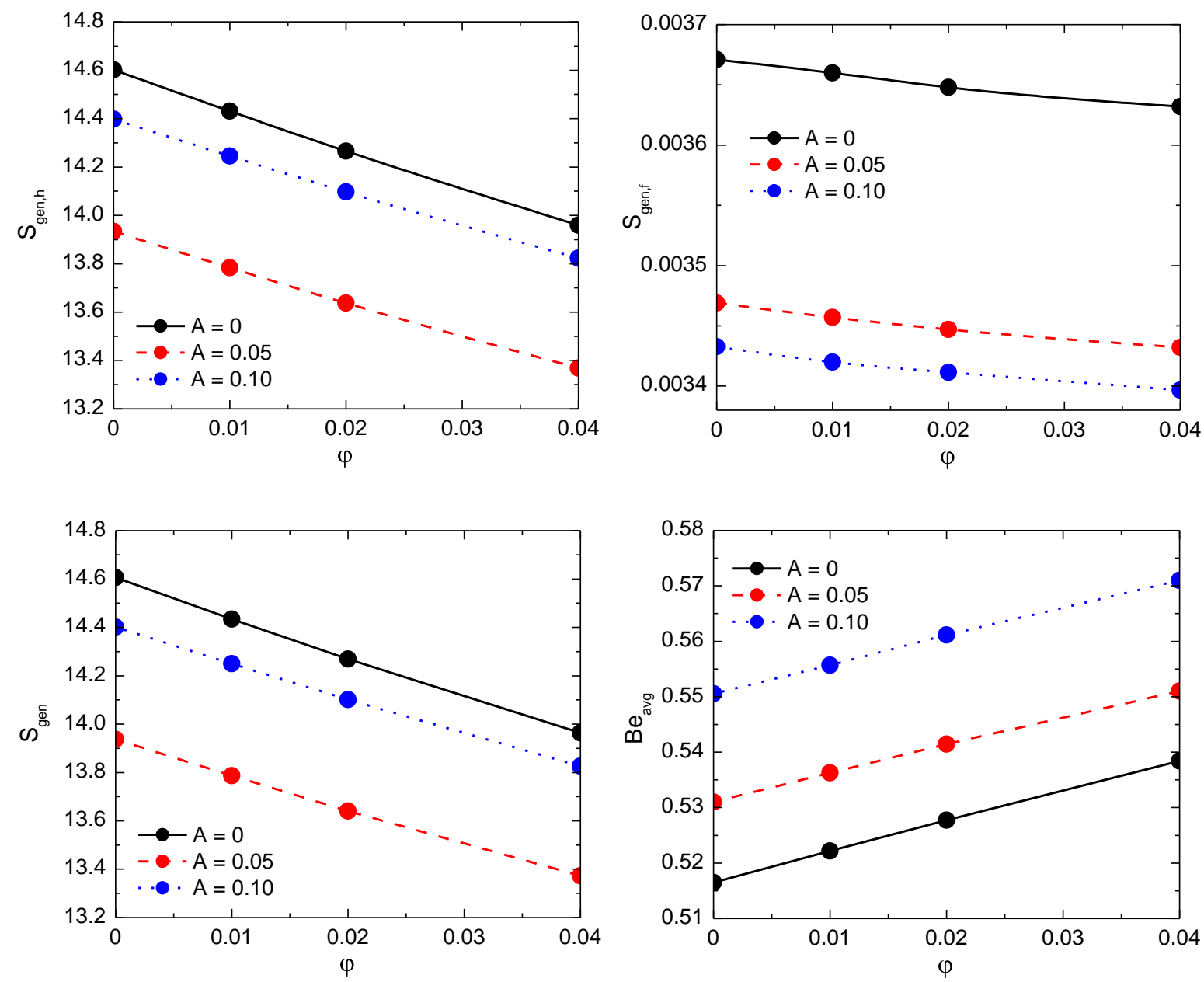

Figure 23. Effects of $\varphi$ on $S_{g e n, h}, S_{g e n, f}, S_{g e n}$ and $B e_{a v g}$ for different values of $A$ when $N=8, \operatorname{Re}$ $=1000$, and $\mathrm{Ra}=10^{5}$. 
Table 1. Thermo-physical properties of base fluid and nanoparticles [30, 42].

\begin{tabular}{|ccc|}
\hline $\begin{array}{c}\text { Thermo-physical } \\
\text { properties }\end{array}$ & $\begin{array}{c}\text { Base fluid } \\
\text { (water) }\end{array}$ & $\begin{array}{c}\text { Nanoparticles } \\
\left(\mathrm{Al}_{2} \mathbf{O}_{3}\right)\end{array}$ \\
\hline$C_{p}(\mathrm{~J} / \mathrm{kg} \cdot \mathrm{K})$ & 4179 & 765 \\
$\rho\left(\mathrm{kg} / \mathrm{m}^{3}\right)$ & 997.1 & 3970 \\
$k(\mathrm{~W} / \mathrm{m} \cdot \mathrm{K})$ & 0.613 & 40 \\
$\beta(1 / \mathrm{K})$ & $2.1 \times 10^{-4}$ & $8.5 \times 10^{-6}$ \\
$\mu(\mathrm{kg} / \mathrm{m} \cdot \mathrm{s})$ & $1.002 \times 10^{-3}$ & - \\
\hline
\end{tabular}

